\title{
30. DETERMINATION OF SEDIMENTARY VELOCITIES USING EXPENDABLE SONOBUOYS AT DSDP LEG 20 DRILLING SITES, NORTHWEST PACIFIC
}

\author{
E. John W. Jones, Department of Geology, University College, London
}

\section{INTRODUCTION}

A determination of the sound velocities in the sediments near each of the sites investigated on Leg 20 of the Deep Sea Drilling Project (Heezen et al., 1972) was attempted by recording an oblique seismic reflection profile using an expendable SSQ-41 sonobuoy and an air gun sound source (Figure 1). The equipment and techniques employed were practically the same as those described by Le Pichon et al. (1968), except that an electrically fired, instead of a free-firing, airgun was used. The latter was triggered every $10 \mathrm{sec}$ with a solenoid valve activated by a switch on the inboard recorder. Simultaneously, a normal incidence profile displayed the configuration of the subbottom layers along the shooting line (Figures 2 to 8 ).

Because of the maneuvering that was often necessary before the precise drilling location was finally established, it was not practicable to shoot the profiles on the approach to each site. The normal procedure was to deploy a sonobuoy on completion of drilling as soon as the ship attained a constant speed of about 5 knots on a steady course to the next site. Because time was at a high premium, at only one site (194) was preliminary positioning of the Glomar Challenger carried out to allow the sonobuoy to be dropped directly over the acoustic positioning beacon. The distances between buoys and their respective drilling sites are listed in Table 1. With the exception of the line on Ita Maitai Guyot, it was necessary to use the sonobuoy hydrophone at its maximum depth of 100 meters to minimize the considerable ship-generated acoustic interference.

Refracted arrivals were not seen on any of the profiles despite the fact that several were shot out to ranges at which refractions from the basement would have been expected. Their absence is probably largely a result of the poor response of the receiving system and recorder filter below $30 \mathrm{~Hz}$.

\section{METHOD OF INTERPRETATION}

In addition to the bottom echo, each oblique reflection profile shows a series of arrivals representing the direct sound transmitted in the surface channel from airgun to sonobuoy (the $D$-wave) and at least one series of reflections from below the sea floor (Figures 2-8). At Sites 194 and 196 to 198, the deepest consistent subbottom echo on the sonobuoy profiles arises from the base of an acoustically transparent layer which constitutes the uppermost sequence of the sedimentary column in this part of the Pacific (Ewing et al., 1968). At other sites, reflections from deeper within the sediments can be distinguished.

The determination of interval velocities was carried out in the stages outlined below, which follow those described by Le Pichon et al. (1968).

\section{Digitization}

Tracings are made of the $D$-wave, bottom, and subbottom reflection curves which are then digitized at $1-\mathrm{mm}$ intervals in the direction of travel of the recording paper. This corresponds to taking readings of arrival times about every $0.06 \mathrm{~km}$ of horizontal range. With the exception of Profile 202, it has been necessary to use an assumed $D$-line, obtained by extrapolation, for points towards the ends of the shooting lines because of early fading of the $D$-wave. The squares of the $D$-wave arrival times are then plotted against the squares of the arrival times of reflections in order to detect obvious errors in the digitization, the presence of small variations in dip along the shooting line, and changes in the ship's speed when the $D$-wave is absent on the record (Figures 9 to 15 ).

\section{Calculation of Velocity of Propagation of the $D$-wave}

If the time-distance curve for the bottom reflection $R_{O}$ starts from zero range, the time of arrival of $R_{O}$ at this range, $T_{0}(0)$, is obtained by a fourth-order, least-squares fit ot $T_{\mathrm{o}}$ and the $D$-wave time; i.e.,

$$
T_{0}=T_{0(0)}+a_{0} D+b_{0} D^{2}+c_{0} D^{3}+d_{0} D^{4}
$$

(where $a_{0}, b_{0}, c_{0}$, and $d_{0}$ are constants and $D$ is the arrival time of the $D$-wave).

If the earliest part of the time-distance curve fails to be recorded (see Sites 194, 198, and 199; Figures 2, 6, and 7) then $T_{0}(0)$ is found from the first-order, least-squares fit of $T_{0}{ }^{2}$ and $D^{2}$,

$$
T_{0}^{2}=T_{0(0)}^{2}+e_{0} D^{2}
$$

where $e_{0}$ is a constant.

Having determined $T_{0(0)}$ and knowing the slope $\omega_{0}$ of the sea floor, the squares of the "reduced times" $T_{0(\mathrm{R})}^{2}$ (see Dix, 1955) are computed using,

$$
T_{0(R)}^{2}=T_{0}^{2}-\left[T_{0(0)}^{2}-2 T_{0(0)} \cdot \sin \omega_{0} \cdot D\right]
$$

The velocity of propagation of the $D$-wave, $V H$, is then obtained by a least-squares fit of $T_{0(R)}^{2}$ and $D^{2}$, since

$$
T_{0(R)}^{2}=D^{2} \cdot \frac{(V H)^{2}}{V_{0}^{2}}
$$

The tables of Matthews (1939) give $V_{0}$ to better than 1 part of 5000 so $\mathrm{VH}$, and hence the ranges corresponding to each point on the bottom and subbottom reflection curves, can be accurately determined. $V H$ values for each site are listed in Table 1. 


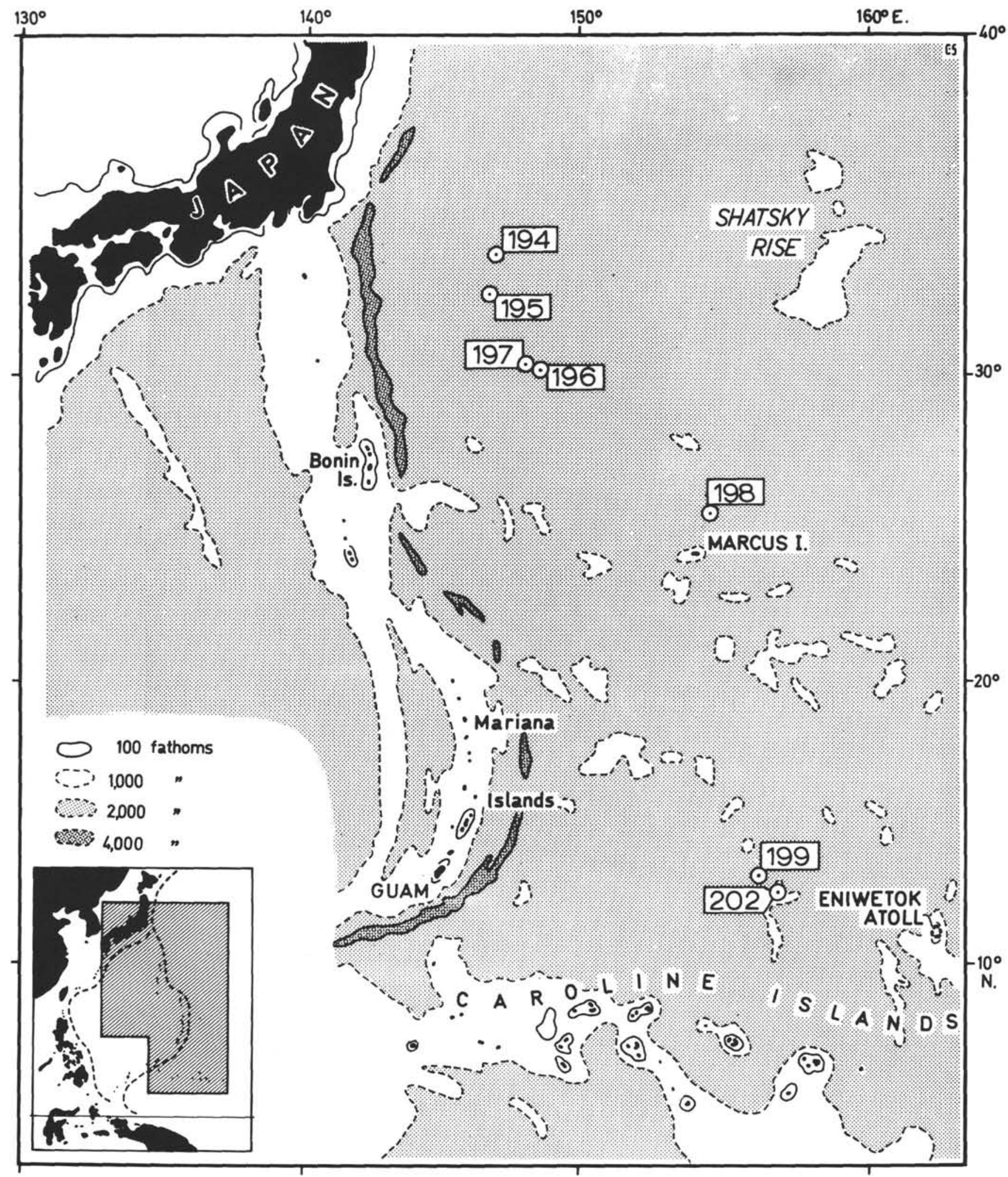

Figure 1. Drilling sites at which oblique reflection profiles were recorded. 

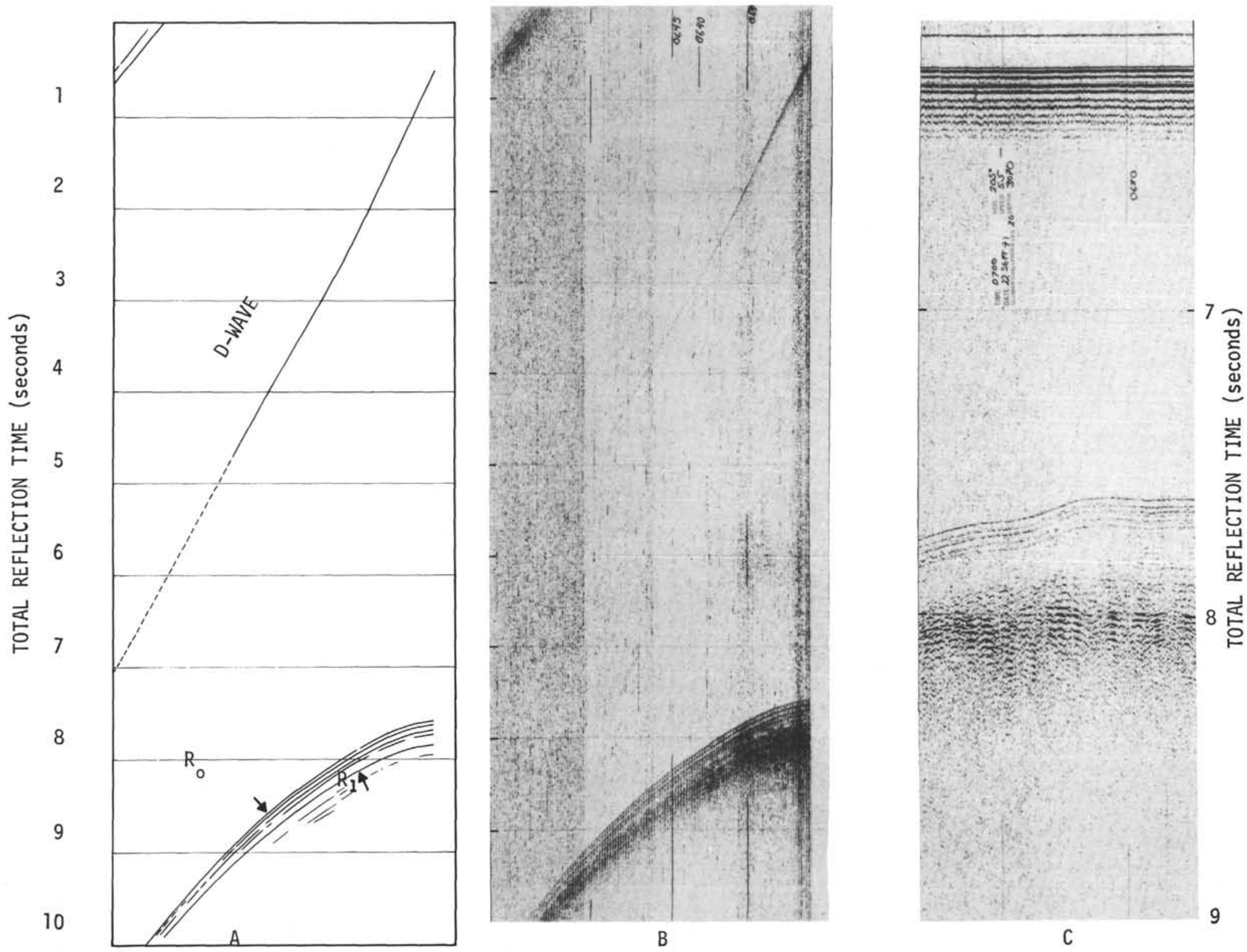

Figure 2. Seismic profiles, Site 194. (A) is a line drawing of principal arrivals on sonobuoy profile $B(40$ to $160 \mathrm{~Hz})$. The corresponding normal incidence profile is $C$ $\left(40\right.$ to $160 \mathrm{~Hz}$ ). Each profile starts from the right-hand side of the record. $\mathrm{R}_{\mathrm{o}}$-bottom reflection. $\mathrm{R}_{1}$-top of the acoustically opaque layer sampled during the drilling. The interval between time marks is 1 sec of two-way reflection time. 


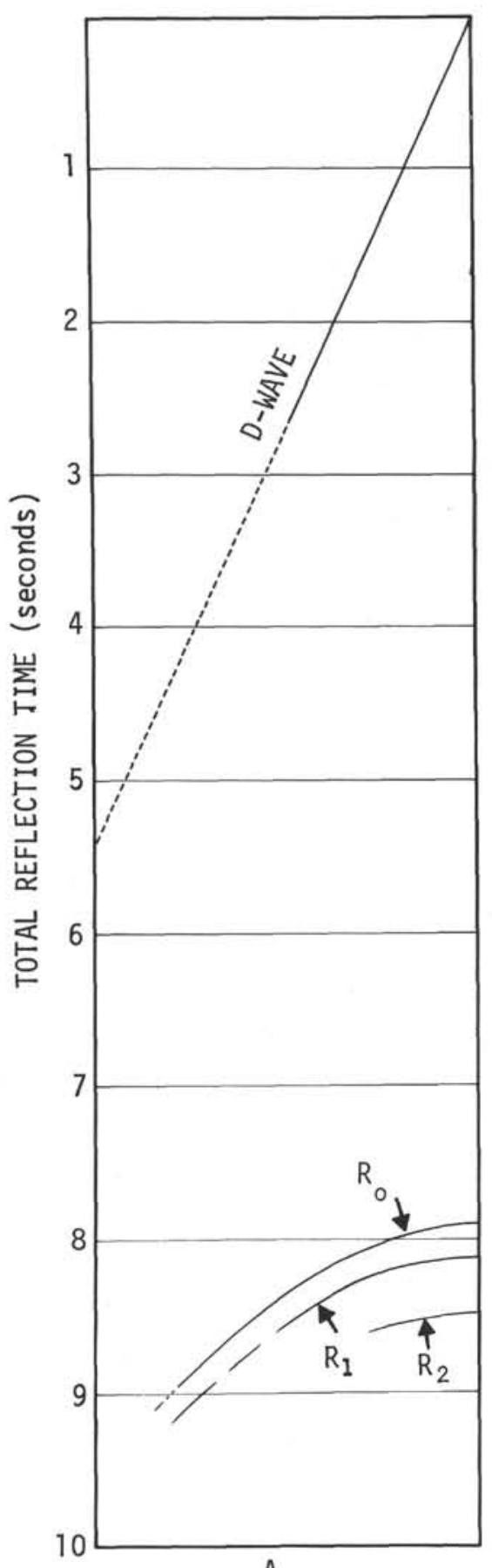

A

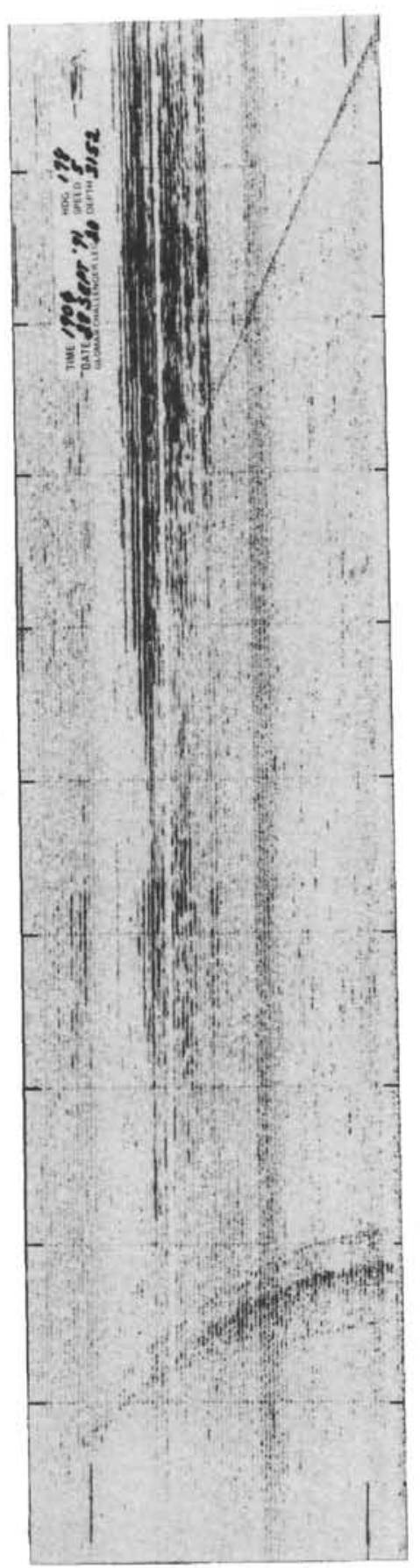

B

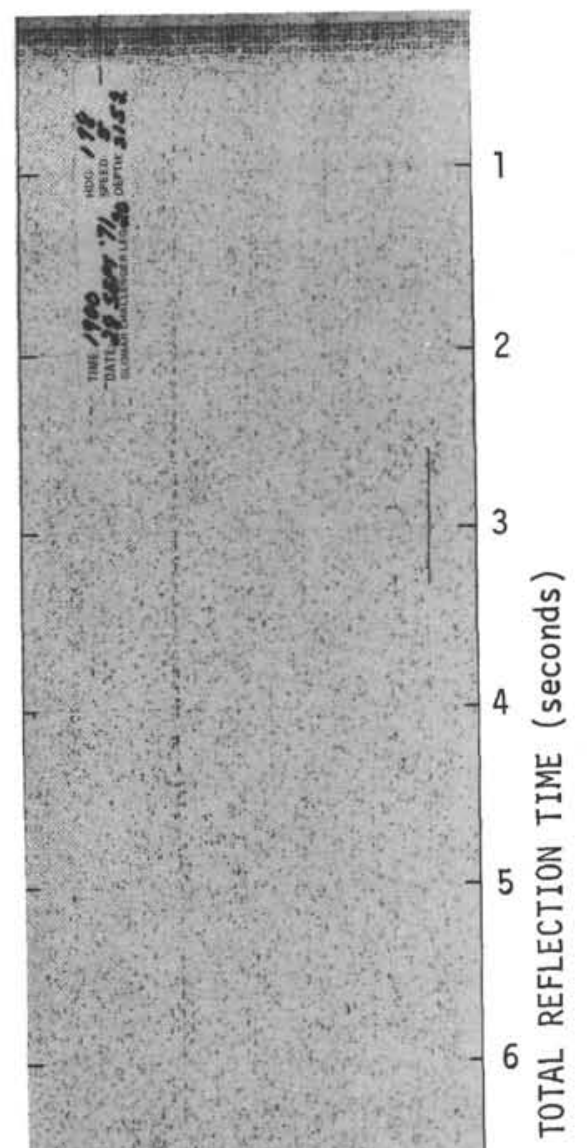

Figure 3. Seismic profiles, Site 195. (A and B) are oblique reflection profiles (40 to $160 \mathrm{~Hz})$. (C) is normal incidence profile $(40$ to $160 \mathrm{~Hz})$. $\mathrm{R}_{\mathrm{o}}$-bottom reflection. $\mathrm{R}_{1}$-reflection from base of the upper acoustically transparent layer. $\mathrm{R}_{2}$-basement reflection.

\section{Velocity in the First Subbottom Layer}

If the curve for $R_{1}$ starts at zero range, then $T_{1(0)}$ is determined from a least-squares fit of $T_{1}$ and $x$ to the fourth-order polynomial

$$
T_{1}=T_{1(0)}+a_{1} x+b_{1} x^{2}+c_{1} x^{3}+d_{1} x^{4}
$$

(where $x$ is the range computed using $V H$ ), otherwise $T_{1(0)}$ is found from a first-order, least-squares fit of $T_{1}^{2}$ and $D 2$.
The angle of ray emergence, $\beta$, at the sea surface is found by differentiation of Equation (5) since

$$
\beta=\sin ^{-1} V_{0} \frac{d T_{1}}{d x}
$$

Knowing $\beta$ and $\omega_{0}$, the time for the ray to travel in the first subbottom layer can be determined by subtracting the time in the water layer from the total reflection time. The 


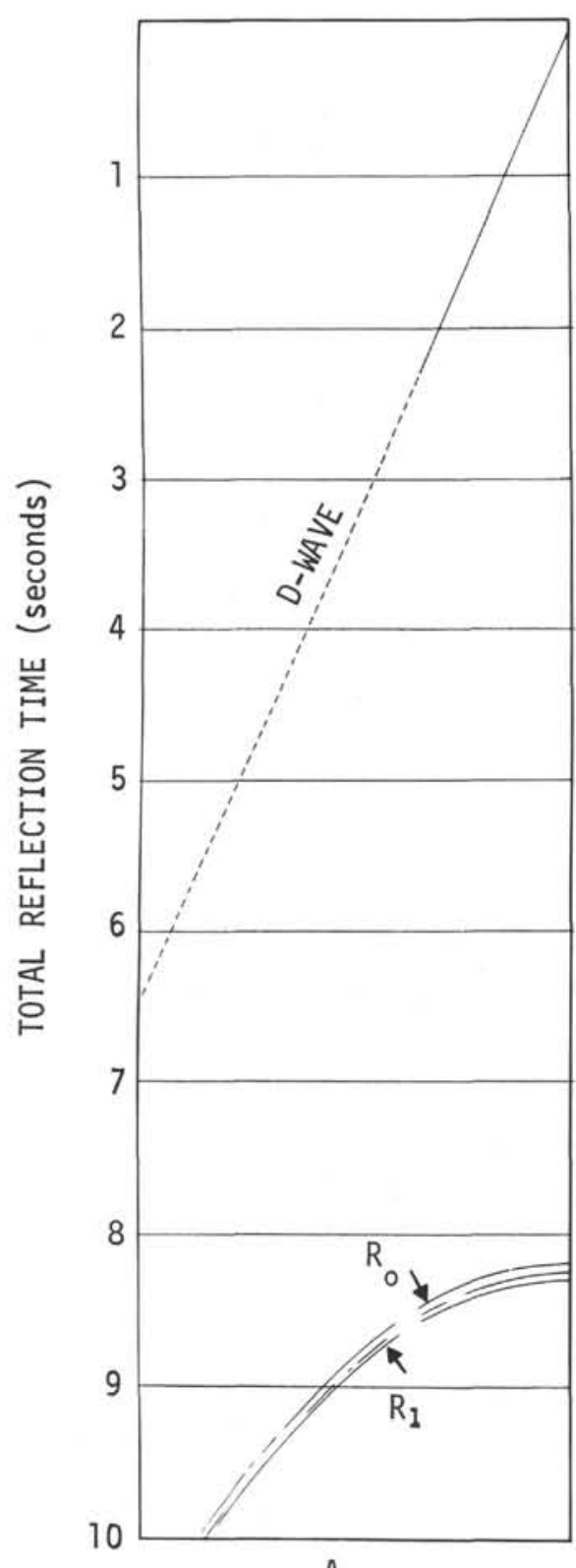

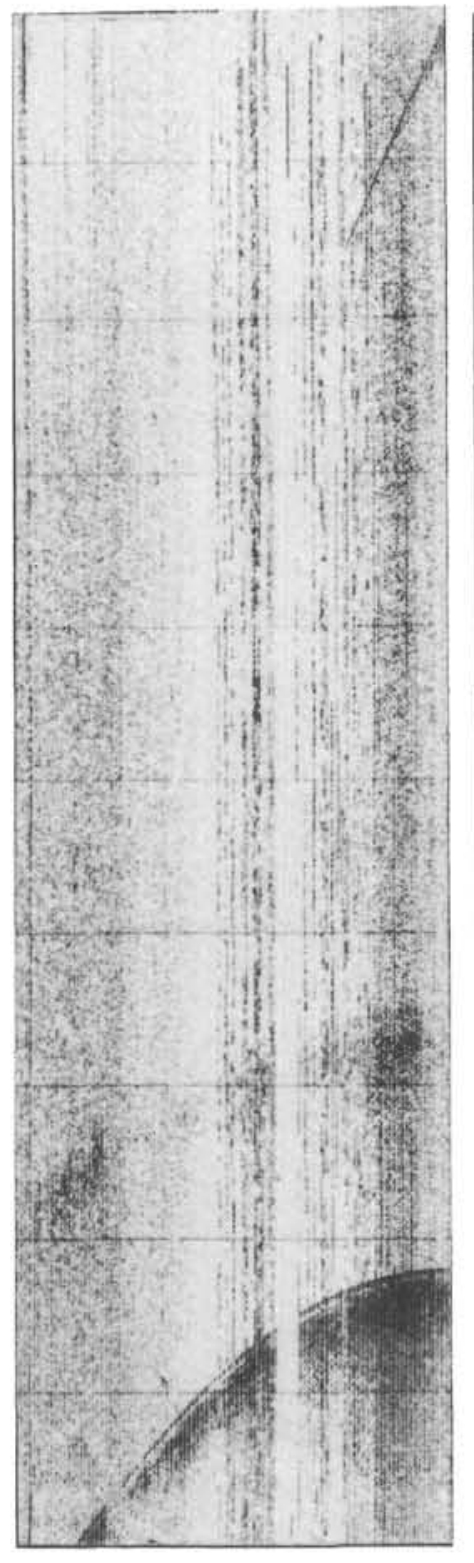

B

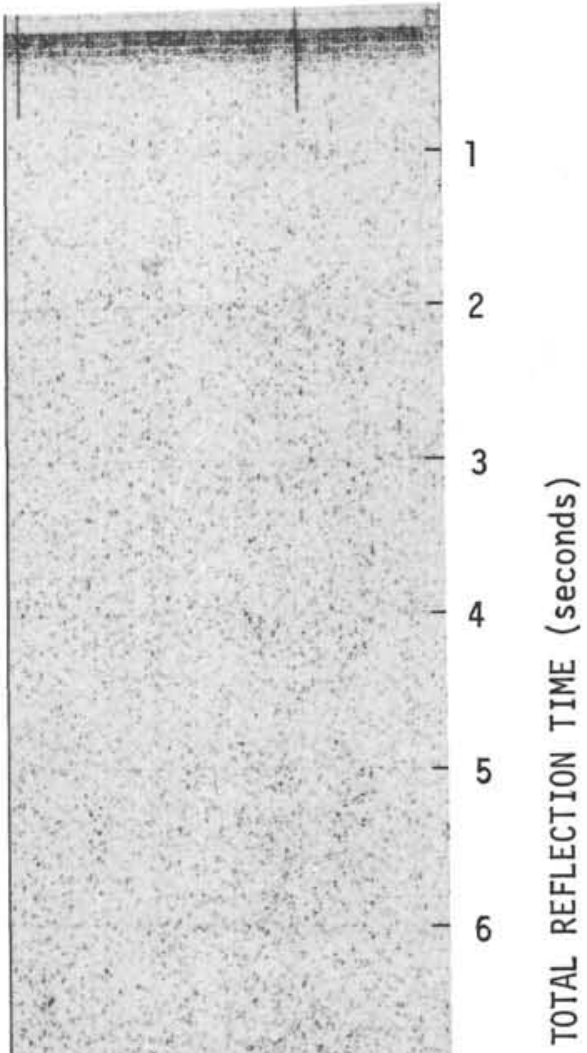

7

8

9

10

Figure 4. Seismic profiles, Site 196. (A and B) are oblique reflection profiles (40 to $160 \mathrm{~Hz}$ ). (C) is normal incidence profile $(40$ to $160 \mathrm{~Hz})$. $\mathrm{R}_{0}$-bottom reflection. $\mathrm{R}_{1}$-reflection from base of the thin transparent layer overlying the acoustically opaque zone.

reduced times $T_{1(R)}$ and reduced ranges $x_{1(R)}$ for the subbottom layer can then be calculated if an approximate value for the dip of its lower interface $\left(\omega_{1}\right)$ is known. A value for the latter is obtained using an assumed velocity in the layer. A first-order, least-squares fit of $I_{1(R)}^{2}$ and $x_{1(R)}^{2}$ gives $1 / V_{1(a)}^{2} \cdot V_{1(a)}$ is then used to give a more accurate value of $\omega_{1}$, and a further fit of $T_{1(R)}^{2}$ and $x_{1(R)}^{2}$ is made. The procedure is repeated until the difference between the velocity used to derive $\omega_{1}$ and the value of $V_{1(a)}$ becomes equal to or less than the standard error of $V_{1(a)}$. In Figure $17, x_{1(R)}^{2}-T_{1(R)}^{2}$ plots for two sites are presented.

At all sites negative values of $T_{1(R)}^{2}$ were encountered. These were found over ranges up to $0.6 \mathrm{~km}$ at Sites 194 ,
195 , and 199 and were eliminated before the least-squares fit of $T_{1(R)}^{2}$ and $x_{1(R)}^{2}$ was made. At Site 202 negative times only occurred at ranges less than $0.4 \mathrm{~km}$. However, at Sites 196, 197, and 198 many negative reduced times were found even toward the ends of the lines. Consequently, a solution for the velocity in the transparent layer could not be obtained. As discussed below, this layer is too thin at these three locations for a velocity measurement by this method.

\section{Velocities in the Second Subbottom Layer}

On Profiles 195, 199, and 202, a well-defined reflecting horizon below the first strong subbottom reflector is 

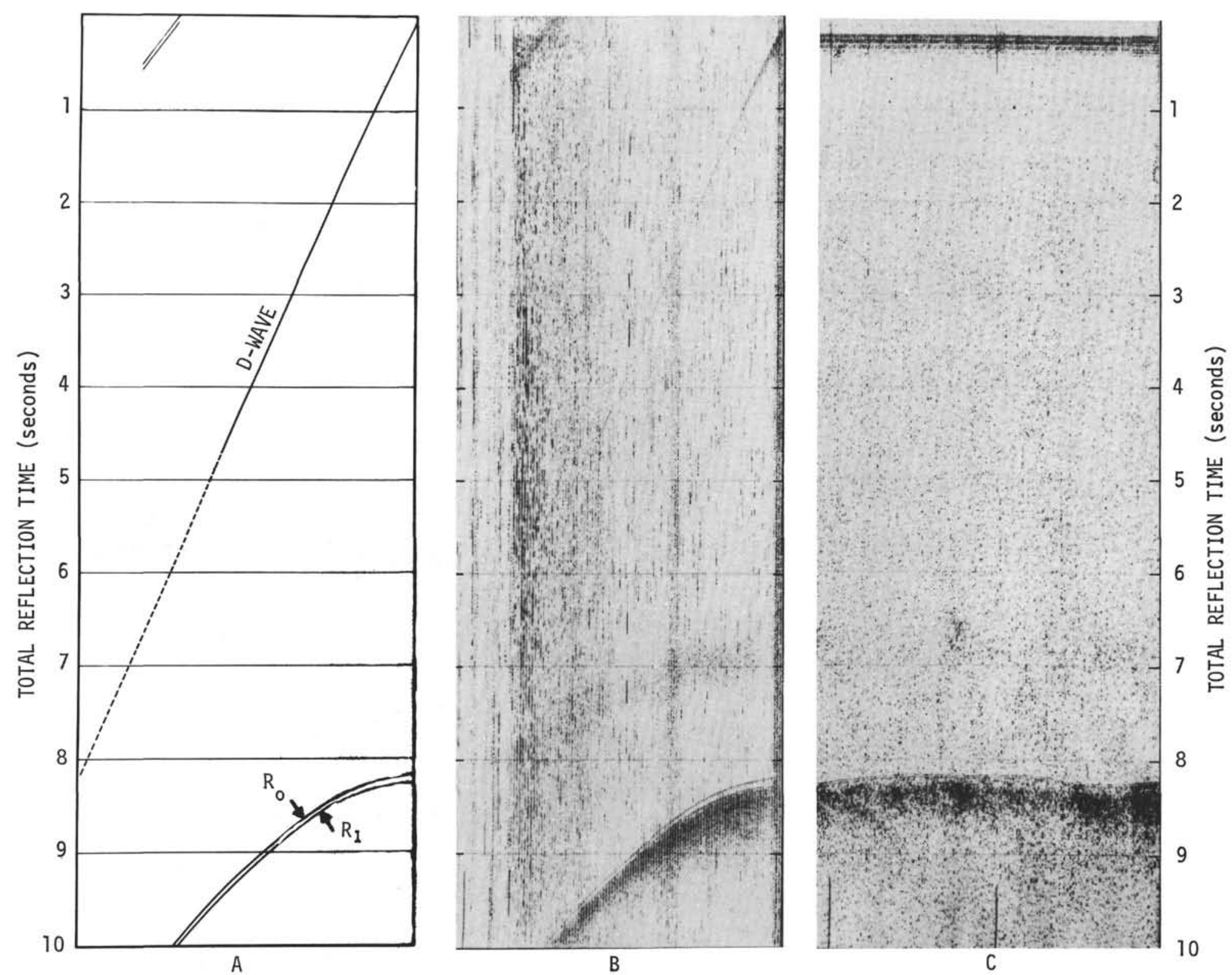

Figure 5. Seismic profiles recorded near Site 197. (A and B) are oblique reflection profiles ( 40 to $160 \mathrm{~Hz}$ ). (C) is normal incidence profile (40 to $160 \mathrm{~Hz}$ ). $\mathrm{R}_{\mathrm{o}}$-bottom reflection. $\mathrm{R}_{1}$-reflection from the base of the thin acoustically transparent layer overlying the opaque zone. In drawing section (A) care was taken to ensure that the pick for $R_{1}$ was not confused with a surface reflection of $R_{0}$. 

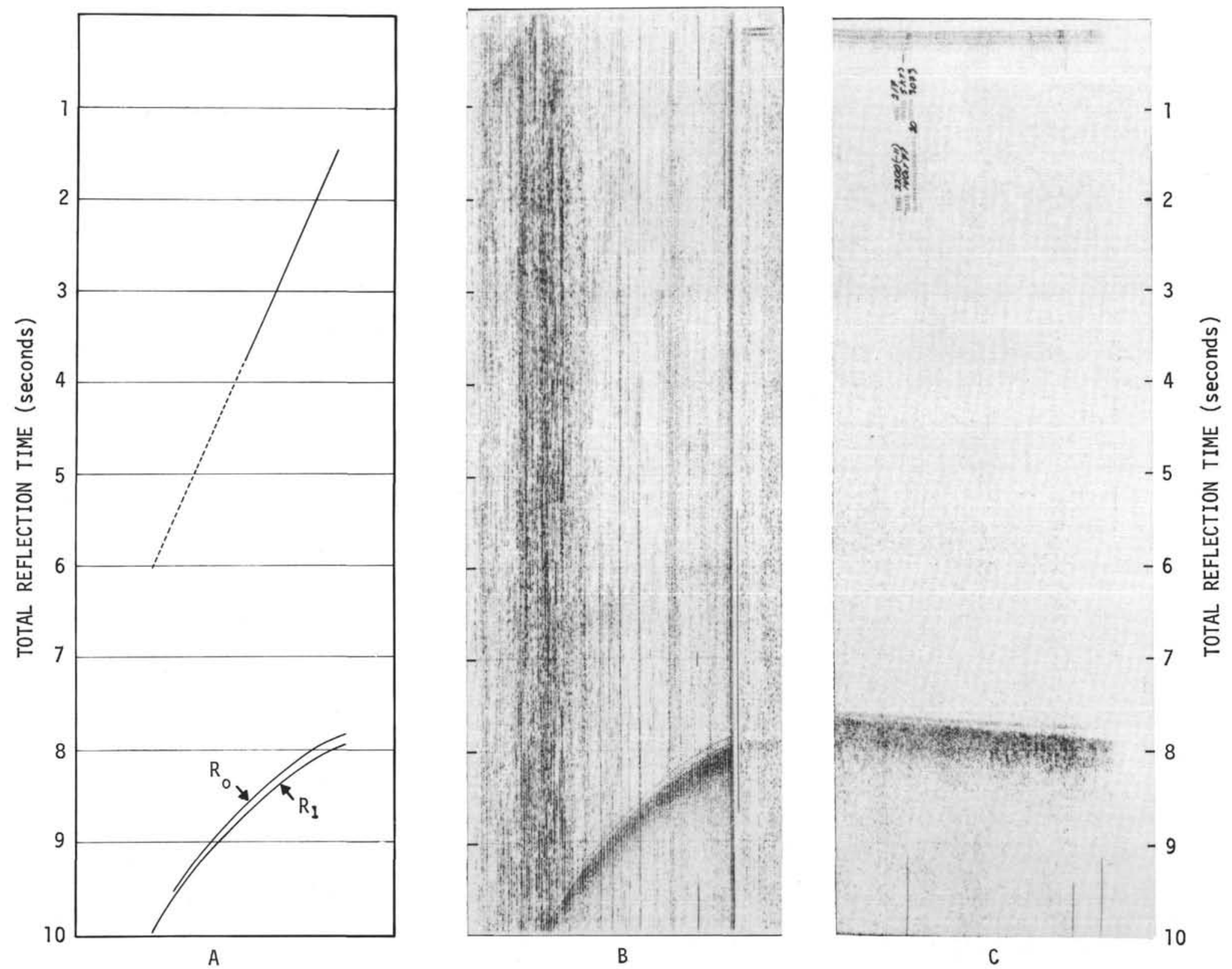

Figure 6. Seismic profiles near Site 198. (A and B) are oblique reflection profiles 40 to $160 \mathrm{~Hz}$ ). (C) is normal incidence profile $(40$ to $320 \mathrm{~Hz})$. $\mathrm{R}_{\mathrm{o}}$ is the bottom echo. $\mathrm{R}_{1}$ arises from the base of the uppermost acoustically transparent layer. 

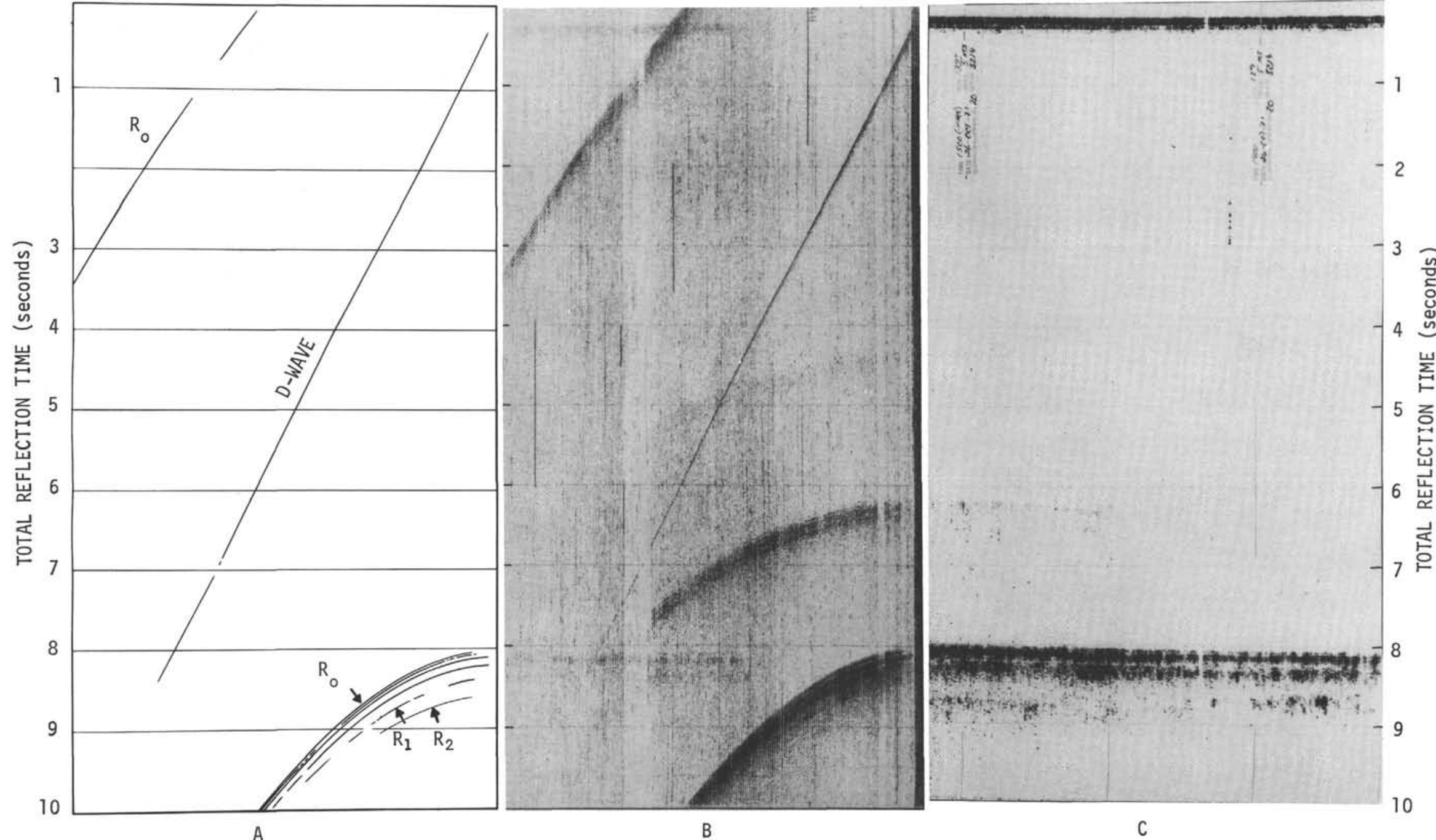

Figure 7. Seismic profiles, Site 199. (A and B) are oblique reflection profiles (40 to $320 \mathrm{~Hz})$. (C) is normal incidence profile $(90$ to $320 \mathrm{~Hz})$. $\mathrm{R}_{\mathrm{O}}$ is the bottom echo. Curves $\mathrm{R}_{1}$ and $\mathrm{R}_{2}$ were used to compute interval velocities. The $\mathrm{D}$-wave on this recording is particularly well developed. 


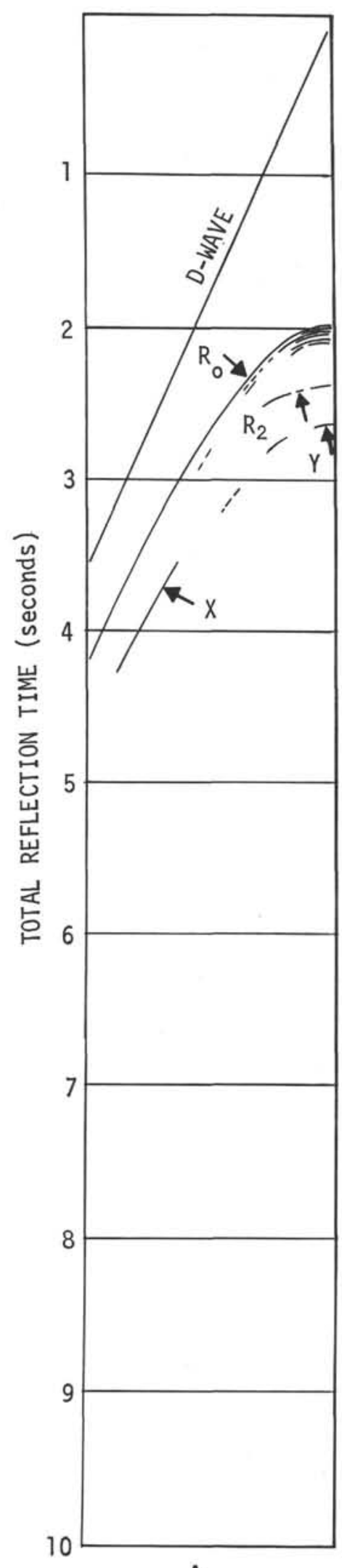

A

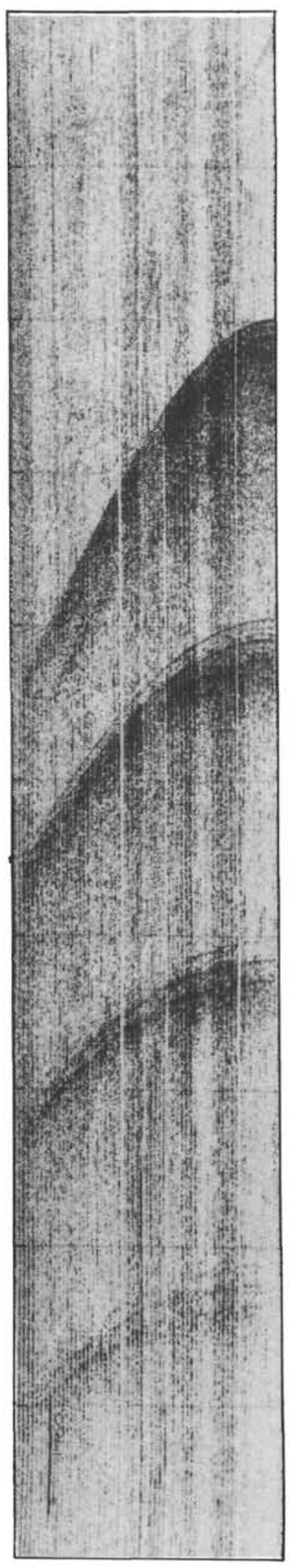

B

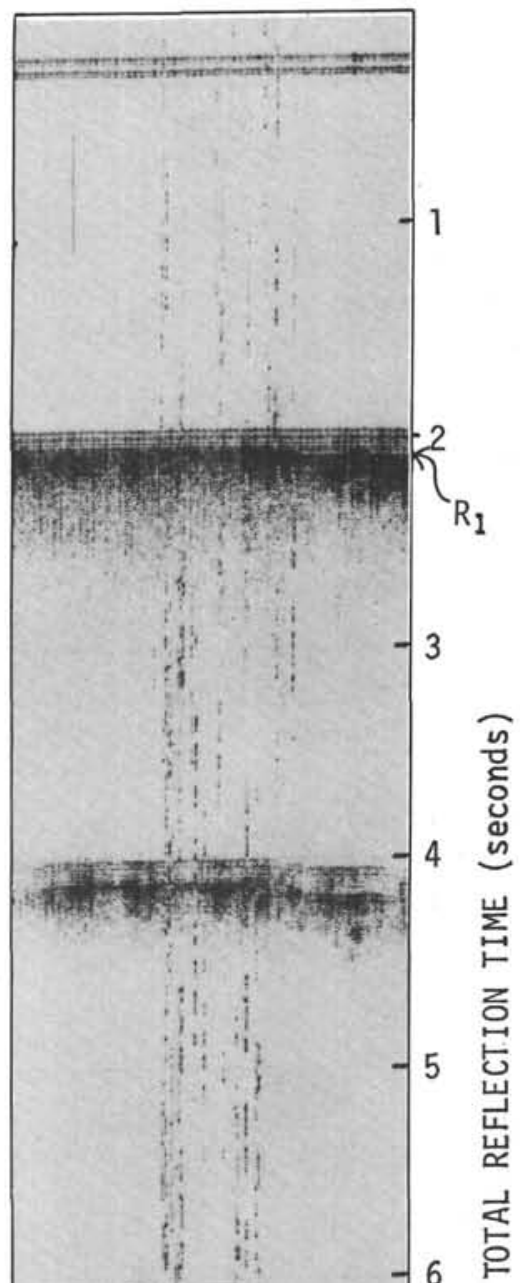

7

8

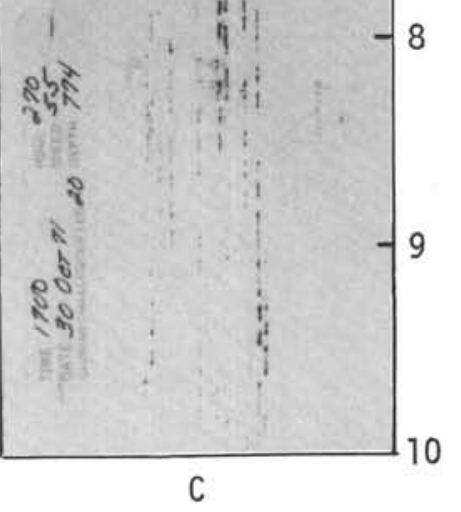

C

Figure 8. Seismic profiles recorded on Ita Maitai Guyot near Site 202. (A and B) are oblique reflection profiles (10 to 160 $\mathrm{Hz}$. (C) is normal incidence section $\left(40\right.$ to $320 \mathrm{~Hz}$ ). $\mathrm{R}_{0}$-bottom echo. $\mathrm{R}_{1}$-the echo from the base of the weakly stratified layer, is not seen on the oblique section. The curve of $\mathrm{R}_{2}$ was used for interval velocity computations. $\mathrm{Y}$ is probably a multiple reflection. X arises from an interface below $\mathrm{R}_{2}$, but cannot be identified at close ranges. 
TABLE 1

Sonobuoy Data

\begin{tabular}{|c|c|c|c|c|c|c|c|c|}
\hline \multirow{2}{*}{$\begin{array}{l}\text { Site } \\
\text { No. }\end{array}$} & \multirow{2}{*}{$\begin{array}{c}\text { Start of Profile } \\
\text { Time Start }\end{array}$} & \multirow[b]{2}{*}{ North } & \multirow[b]{2}{*}{ East } & \multirow{2}{*}{$\begin{array}{c}\text { Water } \\
\text { Depth } \\
\text { Start } \\
(\mathrm{m})\end{array}$} & \multirow[b]{2}{*}{ Time End } & \multicolumn{2}{|c|}{ End of Profile } & \multirow{2}{*}{$\begin{array}{l}\text { Water } \\
\text { Depth } \\
\text { End } \\
\text { (m) }\end{array}$} \\
\hline & & & & & & North & East & \\
\hline 194 & 0613-22 Sep. 1971 & $33^{\circ} 58.3^{\prime}$ & $146^{\circ} 48.4^{\prime}$ & 5740 & $0720-22$ Sep. 1971 & $33^{\circ} 52.7^{\prime}$ & $146^{\circ} 46.0^{\prime}$ & 5853 \\
\hline 195 & 1826-28 Sep. 1971 & $32^{\circ} 40.5^{\prime}$ & $147^{\circ} 03.1^{\prime}$ & 5971 & 1907-28 Sep. 1971 & $32^{\circ} 35.1^{\prime}$ & $147^{\circ} 03.1^{\prime \prime}$ & 5967 \\
\hline 196 & $2313-3$ Oct. 1971 & $30^{\circ} 07.5^{\prime}$ & $148^{\circ} 29.8^{\prime}$ & 6180 & $0002-4$ Oct. 1971 & $30^{\circ} 09.0^{\prime}$ & $148^{\circ} 24.5^{\prime}$ & 6131 \\
\hline 197 & $0223-8$ Oct. 1971 & $30^{\circ} 17.7^{\prime}$ & $147^{\circ} 43.9^{\prime}$ & 6210 & $0330-8$ Oct. 1971 & $30^{\circ} 18.0^{\prime}$ & $147^{\circ} 50.3^{\prime}$ & 6227 \\
\hline 198 & 2114-14 Oct. 1971 & $25^{\circ} 43.8^{\prime}$ & $154^{\circ} 31.0^{\prime}$ & 5861 & 2213-14 Oct. 1971 & $25^{\circ} 38.9^{\prime}$ & $154^{\circ} 27.1^{\prime}$ & 5786 \\
\hline 199 & 1334-26 Oct. 1971 & $13^{\circ} 29.2^{\prime}$ & $156^{\circ} 10.9^{\prime}$ & 6077 & $1508-26$ Oct. 1971 & $13^{\circ} 22.6^{\prime}$ & $156^{\circ} 14.1^{\prime}$ & 6077 \\
\hline 202 & 1634-30 Oct. 1971 & $12^{\circ} 48.9^{\prime}$ & $156^{\circ} 55.1^{\prime}$ & 1455 & $1705-30$ Oct. 1971 & $12^{\circ} 48.9^{\prime}$ & $156^{\circ} 52.0^{\prime}$ & 1448 \\
\hline
\end{tabular}

${ }^{\mathrm{a}}$ Assumed value from Site 194.

${ }^{\mathrm{b}}$ Value assumed from drilling results.

TABLE 1 - Continued

\begin{tabular}{|c|c|c|c|c|c|c|c|c|}
\hline $\begin{array}{l}\text { Length } \\
\text { of } \\
\text { Profile } \\
(\mathrm{km})\end{array}$ & 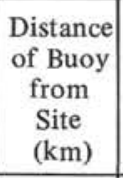 & $\begin{array}{c}V H \mathrm{~km} / \mathrm{sec} \\
( \pm \text { Standard } \\
\text { Error })\end{array}$ & $\begin{array}{c}V_{1} \mathrm{~km} / \mathrm{sec} \\
( \pm \text { Standard Error) } \\
\text { No Water } \\
\text { Refraction } \\
\text { Correction }\end{array}$ & $\begin{array}{c}V_{2} \mathrm{~km} / \mathrm{sec} \\
( \pm \text { Standard Error) } \\
\text { Water } \\
\text { Refraction } \\
\text { Correction }\end{array}$ & $\begin{array}{c}V_{2} \mathrm{~km} / \mathrm{sec} \\
\text { ( } \pm \text { Standard Error) } \\
\text { No Water } \\
\text { Refraction } \\
\text { Correction }\end{array}$ & $\begin{array}{c}V_{2} \mathrm{~km} / \mathrm{sec} \\
( \pm \text { Standard Error) } \\
\text { Water } \\
\text { Refraction } \\
\text { Correction }\end{array}$ & $\begin{array}{c}h_{1} \\
(\mathrm{~km})\end{array}$ & $\begin{array}{c}h_{2} \\
(\mathrm{~km})\end{array}$ \\
\hline 11.0 & 0 & $1.526( \pm 0.0006)$ & $1.90( \pm 0.03)$ & $1.87( \pm 0.03)$ & - & - & 0.24 & - \\
\hline 8.3 & 14.6 & $1.526^{\mathrm{a}}$ & $1.91( \pm 0.07)$ & $1.87( \pm 0.06)$ & $3.08( \pm 0.09)$ & $3.06( \pm 0.09)$ & 0.21 & 0.53 \\
\hline 9.9 & 8.2 & 1.536 & Not determined & - & - & - & - & - \\
\hline 12.5 & 5.5 & 1.507 & Not determined & _ & - & - & _- & - \\
\hline 8.6 & 12.4 & 1.524 & Not determined & - & - & - & - & - \\
\hline 13.8 & 3.1 & $1.530( \pm 0.0007)$ & $1.66( \pm 0.04)$ & $1.62( \pm 0.04)$ & $2.73( \pm 0.05)$ & $2.68( \pm 0.05)$ & 0.28 & 0.30 \\
\hline 5.4 & 3.7 & $1.528( \pm 0.0014)$ & - & $1.60^{\mathrm{b}}$ & $3.85( \pm 0.11)$ & - & 0.11 & 0.53 \\
\hline
\end{tabular}

observed at ranges sufficiently large to establish accurately $T_{2(0)}$ and the coefficients in the equation,

$$
T_{2}=T_{2(0)}+a_{2} x+b_{2} x^{2}+c_{2} x^{3}+d_{2} x^{4}
$$

To compute the velocity in the second subbottom layer, the length of the ray path of $R_{2}$ at range $x$ is found by evaluating the emergent angle $\beta$ from differentiation of Equation (7). Reduced ranges and times for the second subbottom layer are then calculated using a trial value of $\omega_{2}$, the dip of its lower boundary. A first-order, leastsquares fit of $T_{2(R)}^{2}$ and $x_{2(R)}^{2}$ gives the interval velocity $V_{2}$ by the iterative procedure given in the previous section.

\section{Refraction in the Water Layer}

The refraction of sound rays in the water column is not taken into account in the treatment of Le Pichon et al. (1968). Since the thicknesses of the sediment layers at the Leg 20 drilling sites are very small in comparison to the water depth, an assessment of the effect of sound velocity variations in the water was initially made using the sonobuoy recordings from Site 194. These give the most reliable measurement of velocity in the sediments above the acoustically opaque layer on the normal incidence profile. Sound velocities in the water have been calculated from temperature and salinity data collected in the region by Masuzawa (1962). The velocity $v$ (in $\mathrm{cm} / \mathrm{sec}$ ) is obtained from the expression given in Albers (1965).

$$
v=141,000+421 t-3.7 t^{2}+110 S+0.18 d
$$

where $t$ and $S$ are the temperature and salinity at depth $d$ (in $\mathrm{cm}$ ), respectively. To a good approximation, the water layer can be divided into 16 zones as shown in Figure 16. Having determined the emergent angle $\beta$ at the sonobuoy hydrophone, the time taken for the sound to travel along the refracted path through the water is easily determined and substituted in the computer program for the time calculated assuming a straight ray path. As Table 1 shows, the water refraction correction lowers the velocity in the transparent layer by a little over $1 \%$, a difference which is approximately equal to the standard error of the velocity. Applying the correction at Site 199 gives a similar result, whereas at Site 195 the difference between the corrected and uncorrected values is less than the standard error. On profiles 196 to 198 the correction does not appreciably change the number of negative reduced times $\left(T_{1(R)}^{2}\right)$.

\section{DESCRIPTION OF PROFILES}

\section{Site 194}

Upon completion of drilling, Glomar Challenger was maneuvered for a passage at steady speed over the site. Because of an instrument failure after release of the sonobuoy directly above the acoustic beacon, the first 7 min of the reflection profile were not recorded. During the later part of the run, some slight variation in speed occurred 


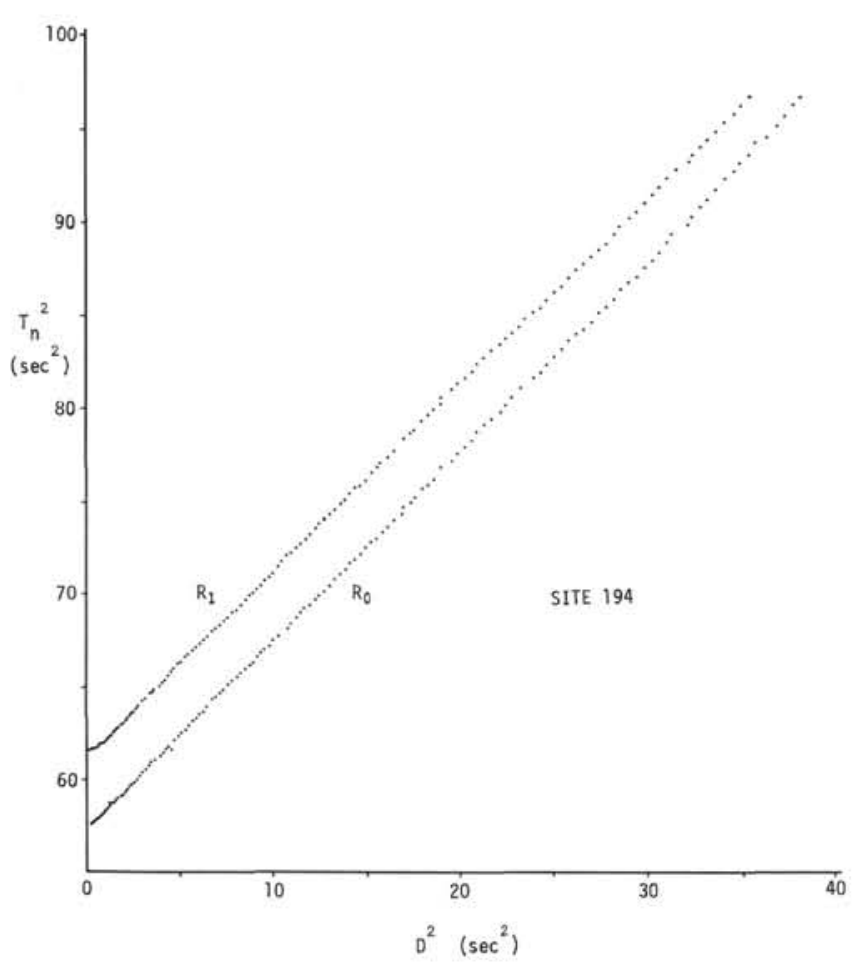

Figure 9. Relationship between the time of arrival (squared) of the $\mathrm{D}-$ wave $\left(\mathrm{D}^{2}\right)$ and the arrival times (squared) of the oblique reflections $\left(\mathrm{T}_{\mathrm{n}}{ }^{2}\right)$, Site 194.

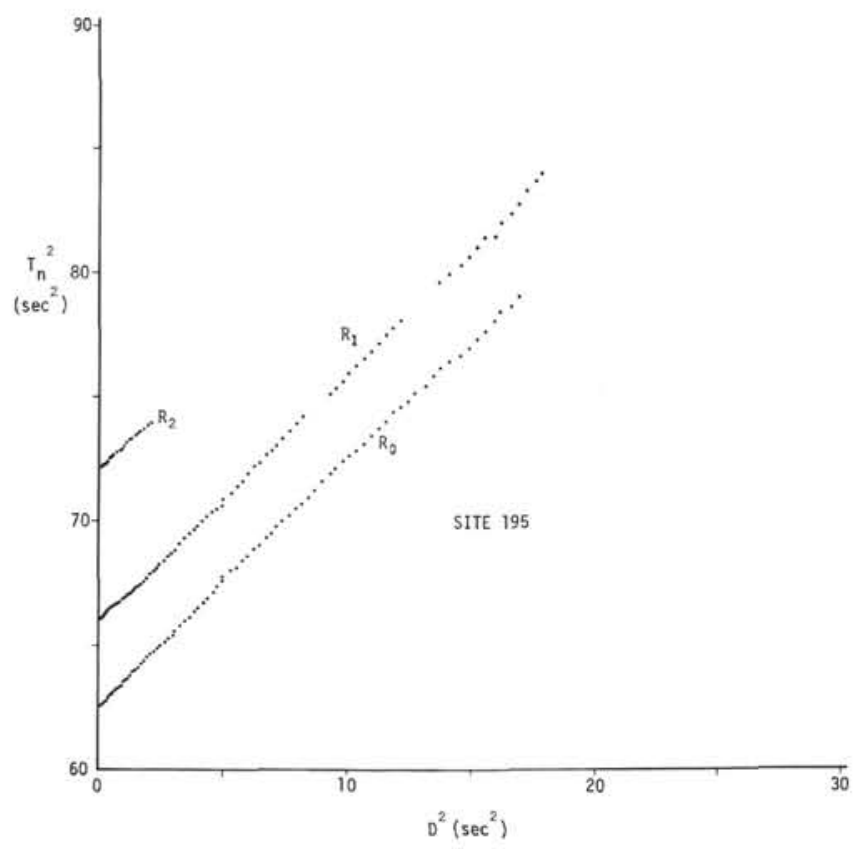

Figure 10. $\mathrm{D}^{2}-\mathrm{T}_{\mathrm{n}}{ }^{2}$ plots, Site 195.

which is made evident by the bending of the $D$-wave line at a range of $2.8 \mathrm{sec}$ (Figure 2).

On both normal and oblique incidence profiles the top of the acoustically opaque layer of Ewing et al. (1968) is clearly recorded (Figure 2). The overlying transparent layer, described by Ewing et al. as being characteristic of a large

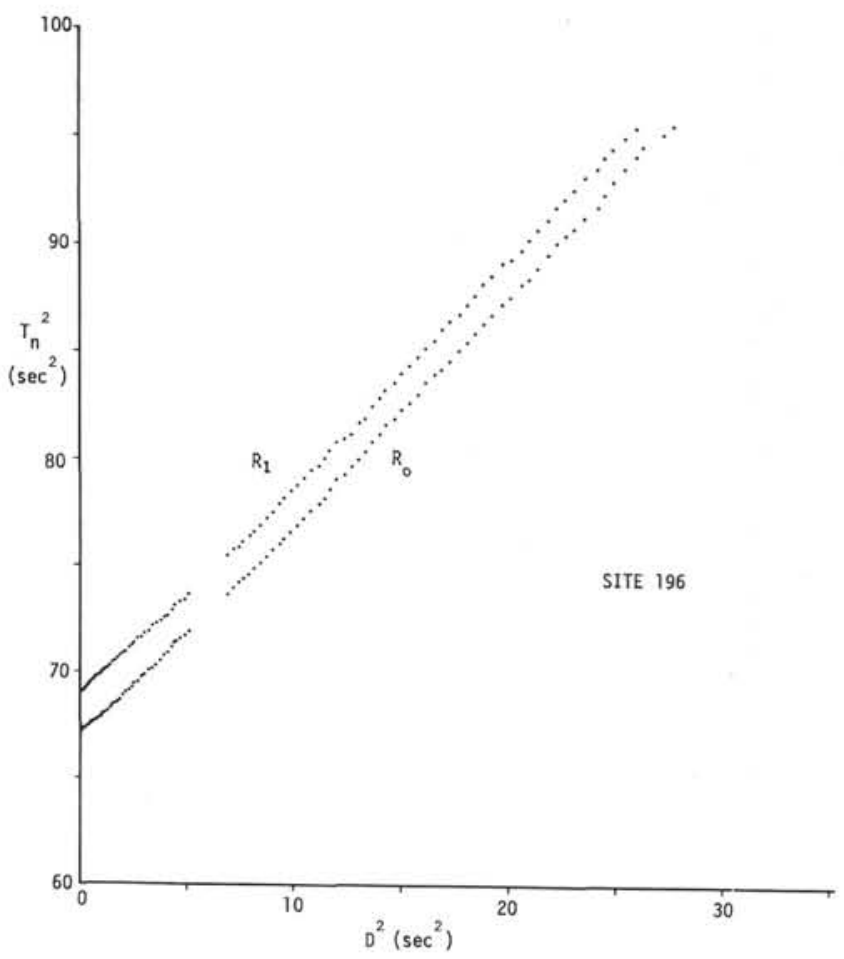

Figure 11. $\mathrm{D}^{2}-\mathrm{T}_{\mathrm{n}}{ }^{2}$ plots, Site 196.

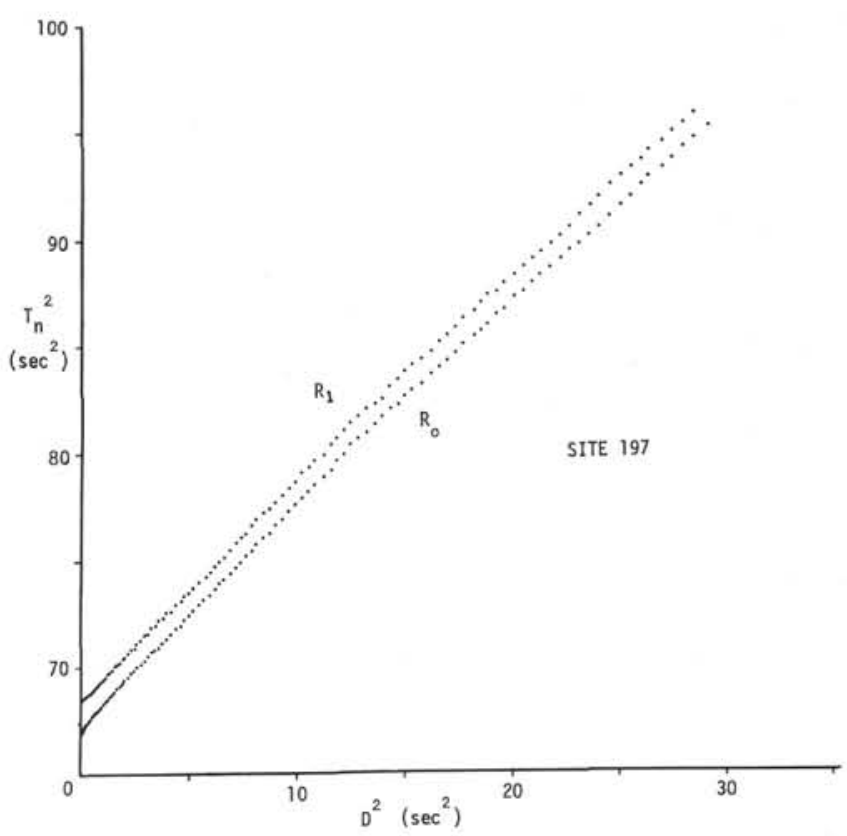

Figure 12. $\mathrm{D}^{2}-\mathrm{T}_{\mathrm{n}}{ }^{2}$ plots, Site 197.

area of the North Pacific, contains here many internal reflectors. This feature may be attributed to the abundance in the abyssal clays of volcanic ash derived from the Japanese arc, a conclusion which receives some support from the drilling (Heezen et al., Chapter 2, this volume). A reflection, probably from the basement, can be seen below the opaque layer, but it is not recorded over a sufficient range to be useful for a velocity measurement. Thus, it is 


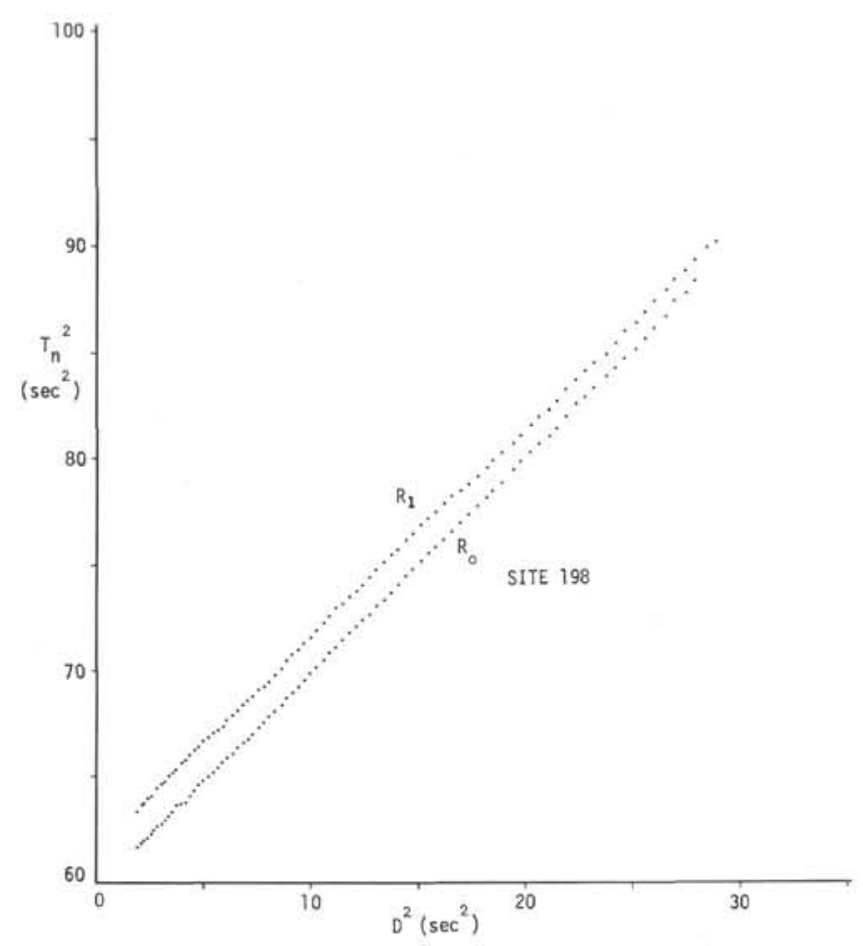

Figure 13. $\mathrm{D}^{2}-\mathrm{T}_{\mathrm{n}}{ }^{2}$ plots, Site 198.

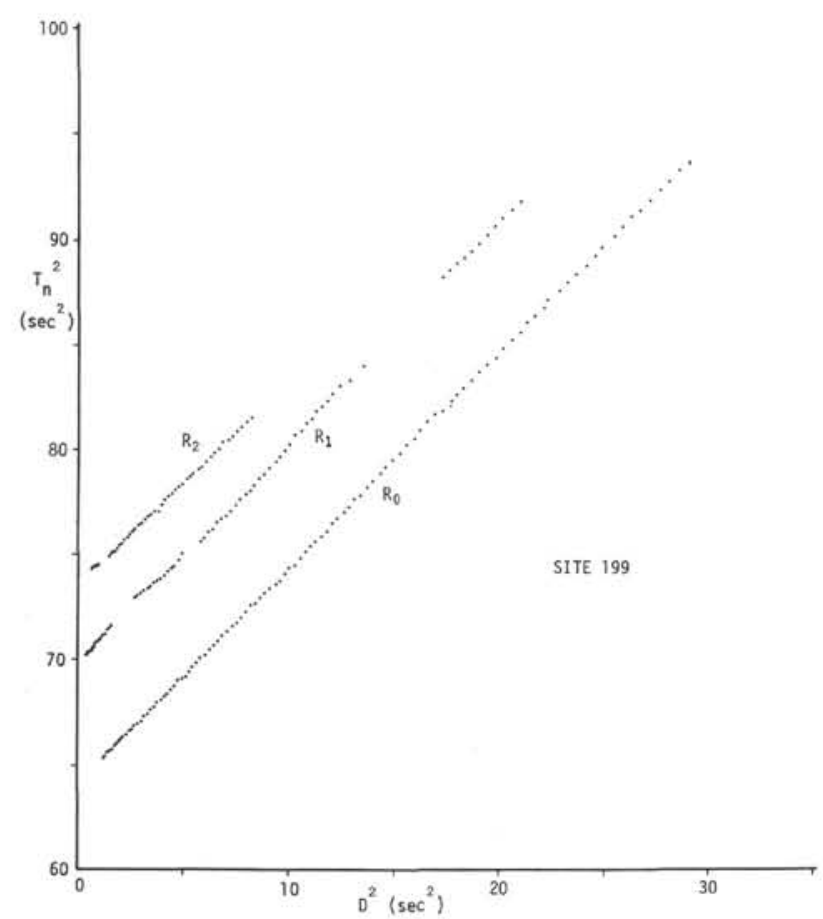

Figure 14. $\mathrm{D}^{2}-\mathrm{T}_{\mathrm{n}}{ }^{2}$ plots, Site 199.

only possible to compute the thickness of the transparent layer. It can be seen on the vertical incidence profile that this layer does vary appreciably in thickness along the shooting line. However, for the first half of the profile, both the sea floor and opaque layer are almost horizontal, making reduction of the data quite straightforward.

The average velocity in the transparent layer is calculated to be $1.87 \mathrm{~km} / \mathrm{sec}$, with a low standard error of 0.03

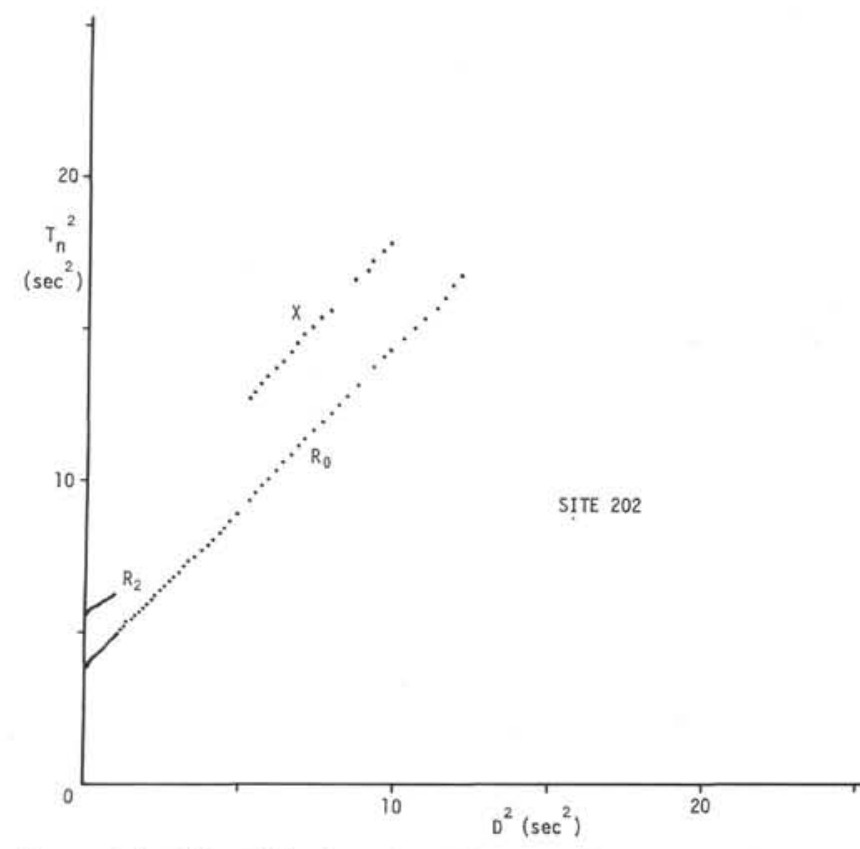

Figure 15. $\mathrm{D}^{2}-\mathrm{T}_{\mathrm{n}}{ }^{2}$ plots for oblique reflections at Site 202.

$\mathrm{km} / \mathrm{sec}$. The simple structure along the path over which the oblique reflections were measured, the well-observed $D$-wave, and the relatively large thickness of the transparent layer make this velocity determination the most accurate in the region of the northern drilling sites.

\section{Site 195}

Throughout the period of recording the signal level was low. The profile had, in fact, to be terminated after only 30 min because noise, generated principally within the recorder, became unacceptable (Figure 3).

The top of the opaque layer is a stronger reflector than the sea floor at this location, and it can be traced out to a range of approximately $6 \mathrm{~km}$. The velocity in the overlying transparent layer is $1.87( \pm 0.06) \mathrm{km} / \mathrm{sec}$, the same value as obtained at Site 194, but one with a higher standard error reflecting the poorer quality record.

Near the beginning of the oblique reflection profile a faint reflector can be distinguished below the top of the opaque layer at $8.6 \mathrm{sec}$ of reflection time. This corresponds to the deepest horizon on the normal incidence section. The reflections appear to arise from the top of the basement which is also seen on recordings made over the approach to the site. No intermediate reflector is discernable on the oblique profile. Accordingly, only the average velocity for the whole of the remaining sedimentary section below the transparent layer can be measured, and this is computed to be $3.06( \pm 0.09) \mathrm{km} / \mathrm{sec}$.

\section{Sites 196, 197, and 198}

The profiles shot near these sites (Figures 4 to 6) are treated together because they all failed to give a velocity value. The only persistent subbottom reflection at each location arises from the top of the opaque layer. Although the reflector can be traced out to the ends of the profiles, the positive values of the squares of reduced times $T_{1(R)}^{2}$ are too few in number and are too widely scattered for a 


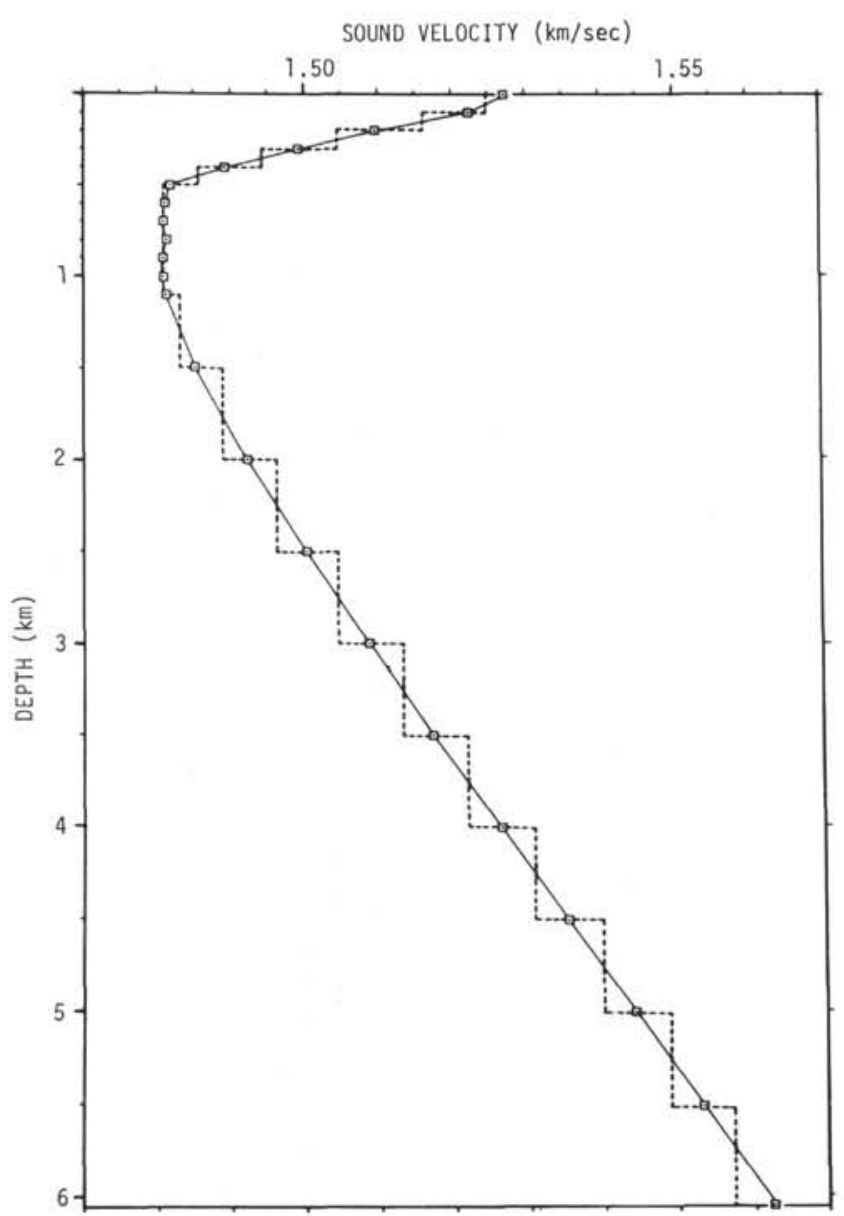

Figure 16. Sound velocity variation with water depth in the region of the drilling sites computed from temperaturesalinity data of Masuzawa (1962). The dotted line shows the approximate velocity function used for cal culating the correction for refraction of the sound rays in the water layer.

reliable measurement of interval velocity. Figure 17 shows the marked difference in the $x_{1(R)}^{2}-T_{1(R)}^{2}$ plots between Sites 194 and 197. Plots from Sites 196 and 198 are similar to the latter. The large spread of points on the $x_{1(a)}^{2}-$ $T_{1(R)}^{2}$ graphs is due to the thinness of the transparent layer. When the time interval between the bottom echo and the reflection from the top of the opaque layer is small, the error in the evaluation of $T_{1(0)}-T_{0(0)}$ is correspondingly large. Furthermore, the differences between the polynomial coefficients in Equations (1) and (5) above become very sensitive to errors in range. The latter are probably larger than can be tolerated when the transparent layer is only about 100 meters thick and the $D$-wave is developed only over short ranges. At Site 197 further errors are introduced by the topographic irregularities and changes in the ship's speed expressed by the relatively large scatter on the $D^{2}-$ $T_{n}^{2}$ plot in Figure 12.

\section{Site 199}

Several reflectors can be followed on the sonobuoy profile, but arrivals from the basement are not detected
(Figure 7). Two horizons which can be correlated with the reflection sequences observed on the normal incidence profile have been chosen for the velocity measurement. One corresponds with the bottom of the youngest laminated zone $\left(T_{1(0)}=8.35 \mathrm{sec}\right)$ and the other with the base of the less stratified succession beneath $\left(T_{1(0)}=8.58 \mathrm{sec}\right)$. The velocity in the top layer, $1.62 \mathrm{~km} / \mathrm{sec}$, is somewhat greater than that in water. An appreciable velocity increase occurs at the base of the laminated zone, as the value below is 2.68 $\mathrm{km} / \mathrm{sec}$ (Table 1).

Site 202

The vertical incidence profile (Figure 8) shows a relatively transparent layer lying upon a strong reflector $\left(R_{1}\right)$ which probably corresponds with the top of the oolitic limestone drilled on the guyot. Instrument gains were set at a high level for recording the sonobuoy output in an attempt to penetrate the limestone. The procedure was successful in that a deep reflection $\left(\mathrm{R}_{2}\right.$ in Figure 8$)$ at a subbottom depth of $0.4 \mathrm{sec}$, which is not present on the vertical incidence section, was detected at short range. However, it resulted in the echoes from the first strong subbottom reflector $\left(R_{1}\right.$ in Figure 8$)$ being obscured. In order to compute the reduced ranges and times for the layer bounded by $R_{1}$ and $R_{2}$, the velocity above $R_{1}$ was taken to be $1.6 \mathrm{~km} / \mathrm{sec}$, a value inferred from the drilling results. $T_{1(0)}-T_{0(0)}$ was read from the vertical incidence record. The velocity in the layer below $R_{1}$ is $3.85( \pm 0.11)$ $\mathrm{km} / \mathrm{sec}$, a figure calculated on the assumption that the $R_{2}$ interface is horizontal for a distance of about 800 meters along the line from the first shot point.

Toward the end of the sonobuoy profile, a series of reflections is observed which appears to arise from an interface well below $R_{2}$ (X in Figure 8). Unfortunately, the reflections are not recorded over a distance sufficient to establish a further interval velocity. The deep echo with a reflection time of $2.62 \mathrm{sec}$ at close range ( $\mathrm{Y}$ in Figure 8 ) is not associated with $\mathrm{X}$, since it appears to be a multiple of $R_{2}$ generated by reflection at the $R_{1}$ interface.

\section{DISCUSSION}

\section{Northern Drilling Sites}

The seismic measurements at Sites 194 and 195 give a value of $1.87( \pm 0.06) \mathrm{km} / \mathrm{sec}$ for the sound velocity in the uppermost acoustically transparent layer characteristically found on reflection records in this region. The thickness of the layer calculated from this value can now be compared with the sections encountered during the drilling operations.

At Site 194 a fairly precise comparison can be made between the seismic and the drilling results (Figures 18 and 19 ) as the sonobuoy was laid directly over the acoustic location beacon. The oblique reflection curves indicate that the base of the transparent layer lies at a depth of 240 meters (Table 1). This is in close agreement with the depth at which the drilling rates decreased and the first cherts so characteristic of the opaque layer of Ewing et al. (1968) were found (Core 3: subbottom depth 227.5 to 237 meters; Heezen et al., Chapter 2, this volume). The difference in depth is somewhat larger than expected from the estimated errors which suggests that the strong reflection from the 

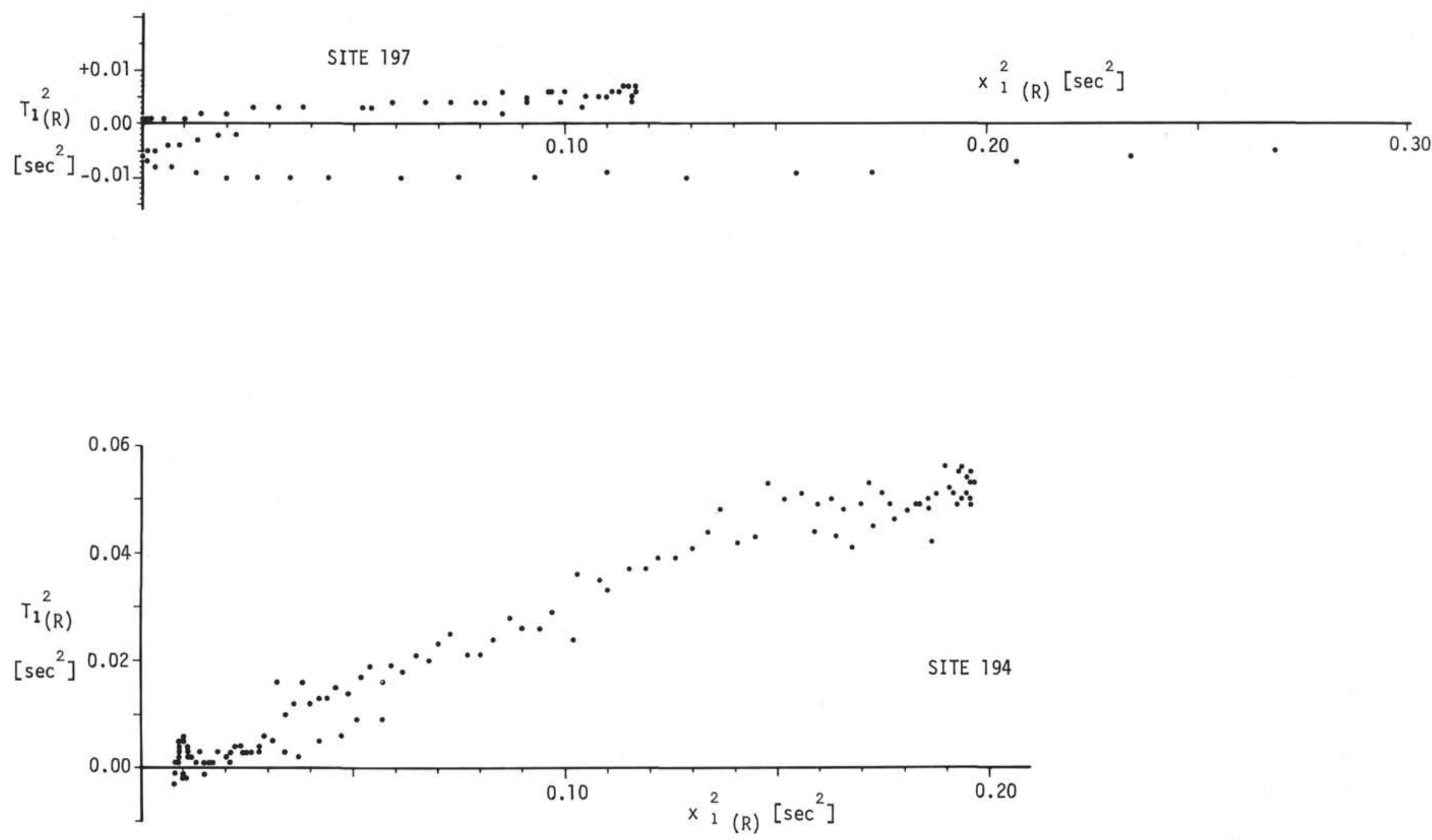

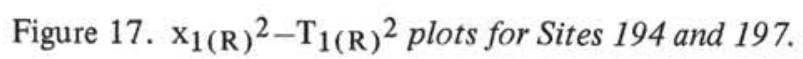


SONOBUOY LITHOLOGY

LAB.

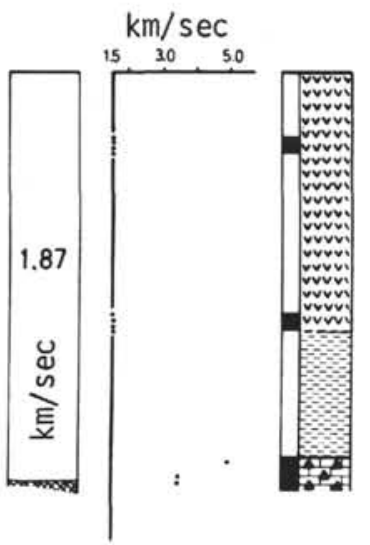

VOLCANOGENIC SED.

TURB IDITES

FORAMINIFERAL SAND

突囯 ABYSSAL CLAY

茞 CHALK

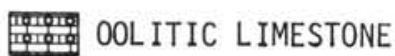

$\Delta \mathbf{\Delta}$ CHERT

透滰 BASALT
SONOBUOY LITHOLOGY

$L A B$.

$\mathrm{km} / \mathrm{sec}$

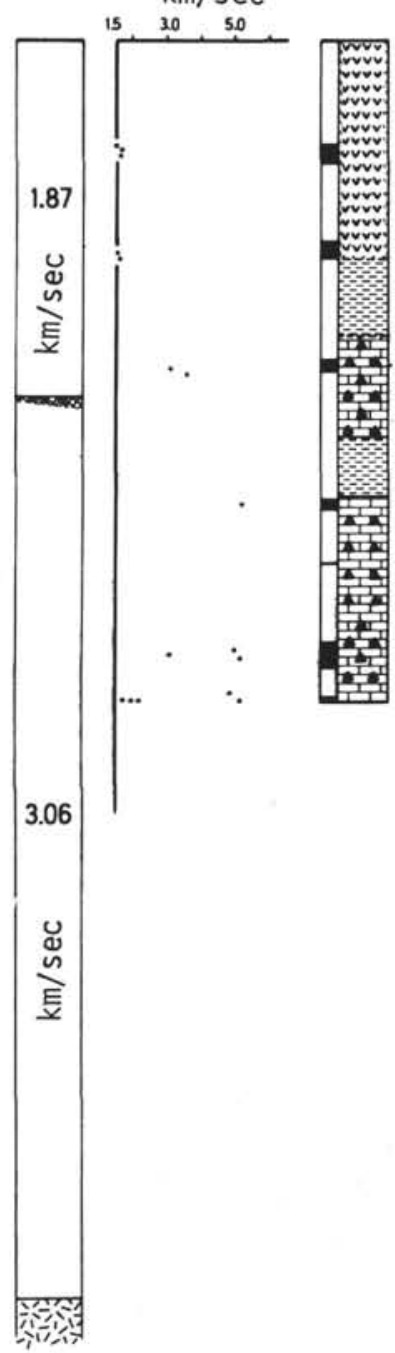

SONOBUOY LITHOLOGY

LAB.

$\mathrm{km} / \mathrm{sec}$

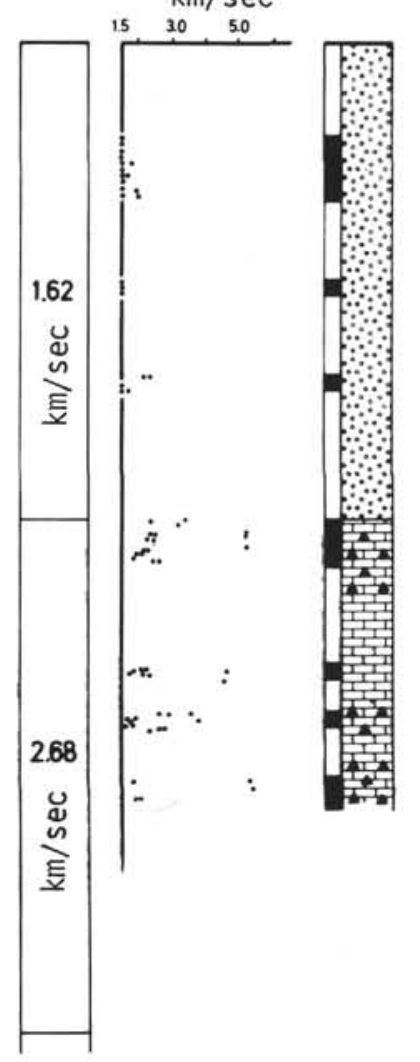

SONOBUOY LITHOLOGY

$L A B$.

$\mathrm{km} / \mathrm{sec}$
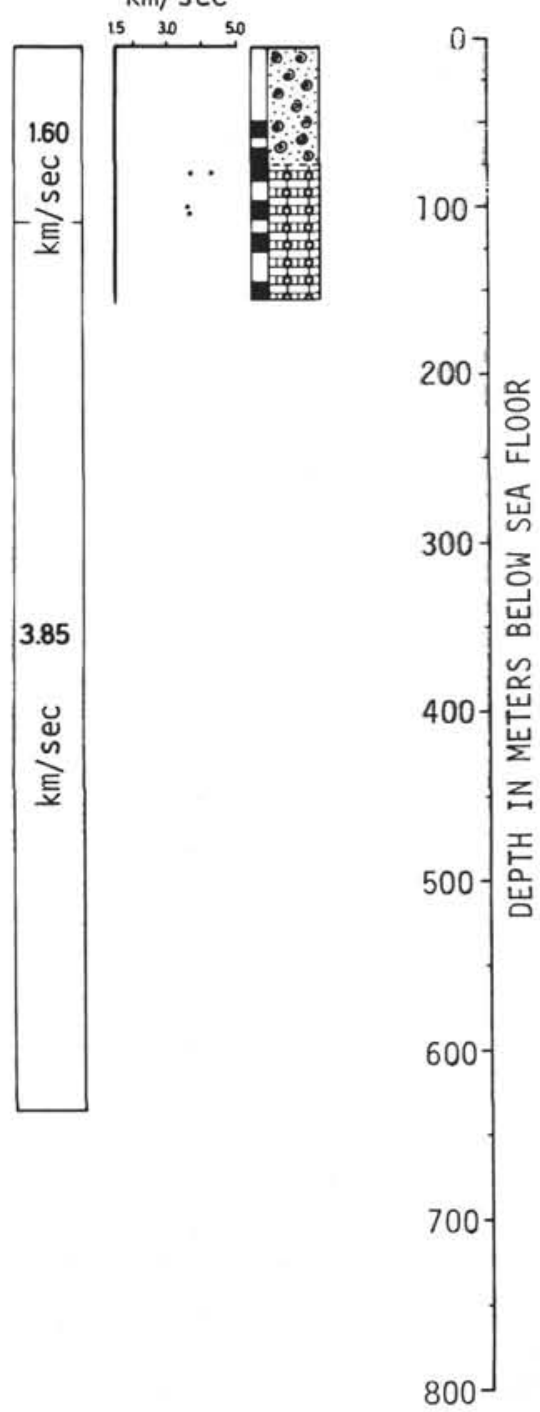

Figure 18. Comparison of seismic measurements and drilling results. The laboratory determinations on the core samples were carried out on the Glomar Challenger by

G. Z. Forristall. Cored intervals are indicated on the left-hand side of the lithologic sections. 

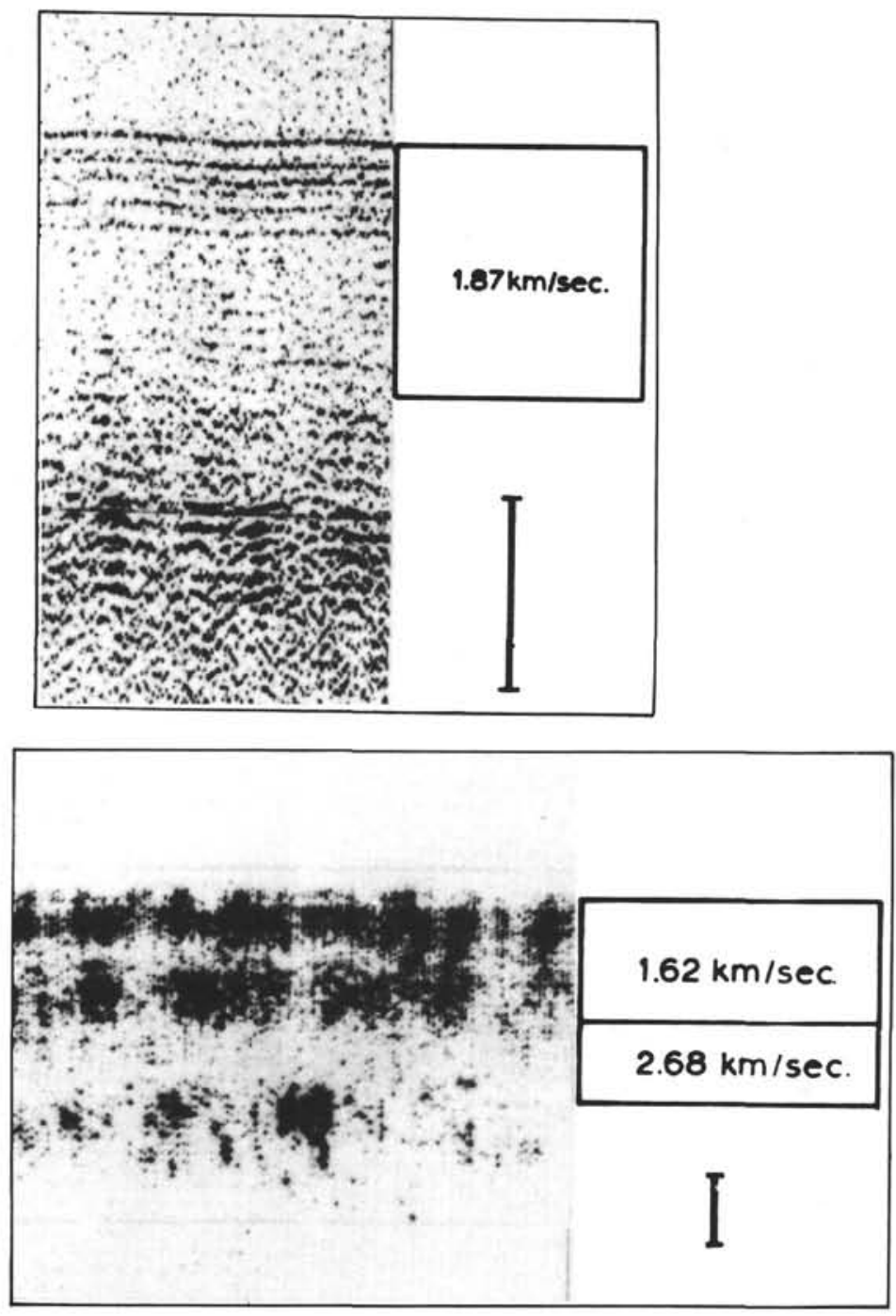

\section{9}
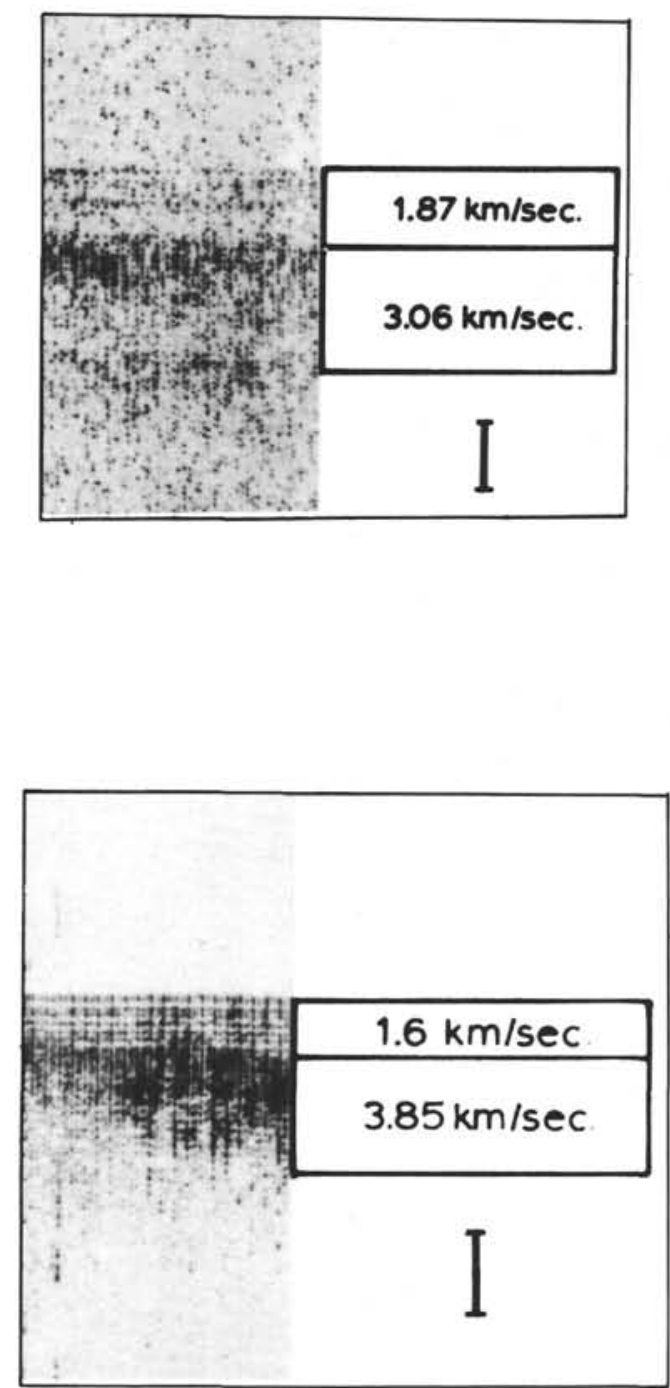

Figure 19. Comparison of the normal incidence sections recorded at the start of each sonobuoy profile and computed layer thicknesses and velocities. Each vertical bar represents $0.2 \mathrm{sec}$ of two-way reflection time.

top of the opaque layer arises a short distance below the youngest part of the chert-bearing sequence.

At Site 195 there is a difference of about 35 meters in the two measurements of the thickness of the transparent layer (Figure 18). It should be noted, however, that the start of the seismic line is some $15 \mathrm{~km}$ from the drilling location. The transparent layer is shown to be somewhat thicker on the reflection record at the drill site. Applying the $1.87-\mathrm{km} / \mathrm{sec}$ velocity there gives a depth of 195 meters to the opaque layer which reduces the above difference in depth by half. The discrepancy of about 15 meters between the seismic and the lithological data is thus about the same as at Site 194. As at Site 194, the top of the opaque layer on the reflection profile lies a few meters below the youngest part of the chert-bearing succession.

The sound velocity in the transparent layer is nearly 0.4 $\mathrm{km} / \mathrm{sec}$ greater than velocities measured in the corresponding core samples by G. Z. Forristall (Heezen et al., Chapters 2 and 3 , this volume) (Figure 18). The difference is rather large but predictable because the 
expansion and mobilization of the clays during the drilling operations would have tended to reduce velocities from their values in situ.

At Site 195 it was possible to measure the seismic velocity in the interval between the base of the transparent layer and the basement (Figure 18), a succession which includes both the opaque and lower transparent layers of Ewing et al. (1968) (Figure 3; normal incidence record). Its high velocity $(3.06 \mathrm{~km} / \mathrm{sec})$ is undoubtedly a result of the preponderance of cherts and chalk; values of 3 to $5 \mathrm{~km} / \mathrm{sec}$ have been measured in these lithologies sampled from the opaque zone (Heezen et al., Chapter 3, this volume). Applying the $3.06-\mathrm{km} / \mathrm{sec}$ value to the observed reflection times at the drilling site gives a basement depth of 620 meters. Thus, about 200 meters of sediments lie beneath the early Hauterivian-Valanginian cherts, marl and chalk being recovered before drilling was terinated.

\section{Caroline Abyssal Plain}

On the Caroline Plain the sonobuoy was deployed close to Site 199 at a location where the depths of the subbottom reflectors are the same as at the drill site. There is good agreement here between the positions of the upper boundary of the $2.68 \mathrm{~km} / \mathrm{sec}$ layer (280 meters; Table 1) and the top of the early Tertiary chert-chalk succession on which turbidites and clays have been deposited (Figure 18). Although the contact between the two sequences was not cored, the change in drilling rate suggests that it lies just above the top of Core 7 of Hole 199 (285.5 meters; Heezen et al., Chapter 00, this volume). Thus the discrepancy between seismic and drilling results is probably less than 10 meters.

The layer above the chert-bearing carbonates has a significantly lower velocity $(1.62 \mathrm{~km} / \mathrm{sec})$ than the transparent layer at the northern drilling sites $(1.87 \mathrm{~km} / \mathrm{sec})$. The difference evidently reflects two distinct modes of deposition. The transparent layer in the north is made up of stiff clays rich in volcanogenic components derived from the nearby island arc, while turbidites form a significant part of the Tertiary accumulations of the Caroline Plain.

It should be noted that the velocities of the majority of the core samples taken from the $1.62-\mathrm{km} / \mathrm{sec}$ layer (Heezen et al., Chapter 7, this volume) lie in the range 1.5-1.7 $\mathrm{km} / \mathrm{sec}$, making the agreement of seismic and laboratory measurements closer at Site 199 than in the north. Between 70 and 100 meters and near 200 meters depth in Hole 199, however, some core samples have higher values (1.8-2.2 $\mathrm{km} / \mathrm{sec}$ ). This is not unexpected because the $1.62-\mathrm{km} / \mathrm{sec}$ layer does contain strong reflectors, indicative of the presence of marked acoustic impedance contrasts (Figure 7) at these levels. It can be seen in Figure 19 that there is a close coincidence of the base of this series of strong and closely spaced reflectors and the bottom of the $1.62-\mathrm{km} / \mathrm{sec}$ layer.

Figure 19 also shows that the limits of the acoustically homogeneous sequence below the laminated zone correlate well with the $2.68 \mathrm{~km} / \mathrm{sec}$ layer, the top 170 meters of which have been shown by drilling to consist of carbonates and cherts. Laboratory measurements on cores from this part of the succession by Forristall (Heezen et al., Chapter 7 , this volume) give a wide range of velocities (1.6-5.3 $\mathrm{km} / \mathrm{sec}$ ), reflecting the lithologic variations, but the majority of samples have velocities greater than $2.5 \mathrm{~km} / \mathrm{sec}$. According to the seismic data, the chalk-chert sequence is at least 300 meters thick (Table 1). Horizontal reflectors at depths greater than $0.58 \mathrm{sec}$ (Figure 19) suggest the presence of a further sedimentary sequence beneath.

It is interesting to record that the Late Cretaceous-early Tertiary carbonates of the Caroline Plain are relatively transparent to the seismic frequencies used for reflection profiling, whereas at the northern drilling sites the carbonate section is highly reflective. As the main acoustic impedance contrasts in the carbonate sequences are probably provided by the cherts they contain, it may be concluded that the acoustically opaque layer at the northern sites is much richer in cherts than the carbonate sections further south. The difference is seismic velocity in the second layer at Sites 195 and 199 supports this inference. At the former site the velocity between the top of the opaque layer and the basement $(3.06 \mathrm{~km} / \mathrm{sec})$ is significantly higher than the velocity of the carbonate-chert layer at Site 199. Part of the $3.06-\mathrm{km} / \mathrm{sec}$ layer at Site 195 would include the abyssal clays believed to lie below the upper opaque zone (Heezen et al., Chapter 7, this volume), so $3.06 \mathrm{~km} / \mathrm{sec}$ may be considered a minimum value for the opaque layer. Its higher velocity may be explained by a greater proportion of cherts within the sequence.

\section{Ita Maitai Guyot}

The oblique reflection profile shot over the guyot is interesting because it reveals a reflector lying well below the top of the oolitic limestone drilled at Site 202. The reflector is not observed on the normal incidence profile (Figure 8 ). The sound velocity in the layer bounded by the deep reflector and the base of the foraminiferal sands is $3.85 \mathrm{~km} / \mathrm{sec}$, which is close to values in core samples of the oolitic limestone recovered at Site 202 (Heezen et al., Chapter 9, this volume). With reflectors absent in this layer, it is reasonable to infer that the deep reflection (labelled $R_{2}$ in Figure 8 ) arises from the base of the limestone, probably at its contact with the underlying volcanics. The shallow-water limestones may thus be estimated to be 525 meters thick, indicating that the total subsidence of the guyot was 2090 meters.

This last figure can be compared to the amount of subsidence of atolls inferred from earlier drilling and seismic observations in the Western Pacific. In Hole F-1 on nearby Eniwetok Atoll (Figure 1) (Ladd and Schlanger, 1960) basalt was reached at 1400 meters after passage of the drill through shallow water calcareous sediments of Eocene age. On Funafuti the calcareous carapace appears to be 1000 meters thick based on the refraction work of Gaskell et al. (1958). Ita Maitai Guyot has therefore subsided appreciably more than these features, but its subsidence is comparable with that of Kwajalein, where Raitt (1954) has shown the limestones to be up to 2000 meters thick. Dredging of reef faunas from the rims of guyots at depths of 2000 meters in the Mid-pacific Mountains (Hamilton, 1956) also indicates sinking of the same order of magnitude. 


\section{ACKNOWLEDGMENTS}

I thank Dr. Terence Edgar, Chief Scientist of the Deep Sea Drilling Project, who arranged for the necessary seismic equipment to be made available for the Leg 20 cruise. Aboard the Glomar Challenger Peter Garrow and Ted Gustafson provided very efficient technical support. I also thank Patricia Jones for her help in digitizing the sonobuoy records and Alan Clewlow for his assistance in preparing the data for computing. The Computer Centre at University College London kindly allowed me time on their IBM 360. Colin Stuart drafted the figures, and Michael Gray photographed the seismic records.

\section{REFERENCES}

Albers, V. M., 1965. Underwater Acoustics Handbook-II: University Pack (The Pennsylvania State University Press), $356 \mathrm{p}$.

Dix, C. H., 1955. Seismic velocities from surface measurements: Geophysics, v. 20, p. 68.

Ewing, J., Ewing, M., Aitken, T., and Ludwig, W., 1968. North Pacific sediment layers measured by seismic profiling: In The Crust and Upper Mantle of the Pacific Area, Geophys. Monogr. 12, Washington (American Geophysical Union), p. 147.

Gaskell, T. F., Hill, M. N., and Swallow, J. C., 1958. Seismic measurements made by H.M.S. Challenger in the
Atlantic, Pacific and Indian oceans and in the Mediterranean Sea, 1950-53: Phil. Trans. Royal. Soc. London A. 251, p. 23 .

Hamilton, E. L., 1956. Sunken islands of the Mid-Pacific Mountains: Geol. Soc. Am. Mem., v. 64, p. 97.

Heezen, B. C., MacGregor, I. D., Foreman, H. P., Forristall, G. Z., Hekel, H., Hesse, R., Hoskins, R. H., Jones, E. J. W., Kaneps, A., Krasheninnikov, V. A., Okada, H., and Ruef, M. H., 1972. Deep Sea Drilling Leg 20: Geotimes, v. 17 , p. 10 .

Ladd, H. S. and Schlanger, S. O., 1960. Drilling operations on Eniwetok Atoll: U.S. Geol. Survey Prof. Paper 260-Y, p. 863.

Le Pichon, X., Ewing, J., and Houtz, R. E., 1968. Deep sea sediment velocity determination while reflection profiling. J. Geophys. Res., v. 73, p. 2597.

Masuzawa, J., 1962. The Deep Water in the western boundary of the North Pacific: J. Oceanog. Soc. Japan. 20th Anniv. Vol., p. 279.

Matthews, D. J., 1939. Tables of the velocity of sound in pure water and sea water for use in echo sounding and sound ranging H.D. 282: London (Hydrographic Department, Ministry of Defense).

Raitt, R. W., 1954. Seismic refraction studies of Bikini and Kwajalein Atolls: U. S. Geol. Survey Prof. Paper 260-K, p. 507. 